\title{
Indicadores de gestión para el programa de generación de ingresos para la población desplazada en Colombia*
}

\section{Management indicators for the program of income generation}

For the displaced population in Colombia

\author{
Gilberto Enrique Herazo Cueto** \\ Rubén Herazo Periñan*** \\ Claudia Milena Sánchez Cruz***** \\ Alexander Sellamén Garzón******
}

* Artículo resultado de la investigación del proyecto: Evaluación de Impactos Financieros y Económicos del Programa de Generación de Ingresos para la Población Desplazada en Colombia, aprobado y apoyado en el marco de la Sexta Convocatoria Interna de Proyectos de Investigación liderada por la Vicerrectoría Académica General - Unidad de Investigación de la Universidad Santo Tomás, Bogotá - Colombia (2010 - 2011).

** Economista, Magíster en Planeación Socioeconómica, Especialista en Docencia y Especialista en Proyectos de Desarrollo, Docente de la Facultad de Economía de la Universidad Santo Tomás - Bogotá, Colombia, miembro del Centro de Investigaciones Económicas Louis Joseph Lebret, O.P. Correo: gilbertoherazo@usantotomas.edu.co.

*** Administrador de Empresas, Magíster en Ciencias Económicas, Especialista en Proyectos de Desarrollo, Especialista en Gerencia Financiera, Docente Asociado de Tiempo Completo de la Universidad Militar Nueva Granada. Correo: ruben.herazo@unimilitar.edu.co

**** Economista y Especialista en Proyectos de Desarrollo, Asesor Académico y profesional especializado de la Dirección de Regulación, Planificación y Normalización DIRPEN del Departamento Administrativo Nacional de Estadística-DANE. Correo: cmsanchezc@dane.gov.co

***** Economista y Magíster en Gobierno y Políticas Publicas, Docente de la Facultad de Economía de la Universidad Santo Tomás - Bogotá, Colombia. Correo: alexandersellamen@usantotomas.edu.co. 
Recibido: 11 de mayo de 2015

Revisado: 2 de junio de 2015

Aprobado: 8 de junio de 2015

\section{Resumen}

En este documento se construyen y estiman indicadores de gestión a partir de criterios de eficiencia, oportunidad y efectividad, para analizar y/o evaluar parcial e integralmente el Programa de Generación de Ingresos para la población desplazada ofrecido por una Oficina Operadora entre mayo de 2007 y marzo de 2008 en el marco del Convenio 082 entre Acción Social y CHF Internacional. Los resultados muestran que existieron fallas en la implementación del programa que no permitieron la efectividad del mismo ni la continuidad de sus participantes hacia un proceso de estabilidad socioeconómica. Los indicadores que aquí se construyen podrían aplicarse en la evaluación de implementación de este tipo de programas, fortaleciendo algunos aspectos de la gestión pública.

Palabras clave: Programa de Generación de Ingresos (PGI), Evaluación, Indicadores de Gestión, Eficiencia, Oportunidad y Efectividad, Desplazamiento Forzado, Gestión Pública.

Clasificación JEL: D24, G30, G32

\section{Abstract}

In this paper, management indicators are constructed and estimated from considerations of efficiency, timeliness and effectiveness to evaluate partial and fully the Income Generation Program for IDP offered by an Office Operator between May 2007 and March 2008 under the 082 Agreement between CHF International and Acción Social. The results show that there were flaws implementing the program that prevented the effectiveness and continuity of its participants to a process of socio-economic stability. The indicators could be applied in terms of evaluation of implementation of such programs, strengthening some aspects of governance.

Keywords: Income Generation Programs (PGI), Assessment, Management Indicators, Efficiency, Opportunity and Effectiveness, Forced Displacement, Public Management.

Classification JEL: D24, G30, G32 


\section{Introducción}

Desde 2005, la Política Pública de Atención al Desplazamiento ha sido objeto de constantes debates y reflexiones debido a su connotación socioeconómica. Tanto así que los programas, como componentes garantes y su misma promulgación, se han venido reorientando desde un enfoque focalizado hasta una directriz jurídica. Sin embargo, desde esta perspectiva no han sido suficientes las intervenciones para tratar de mitigar el fenómeno ni mucho menos para acabar con su causa; esto permite abordar el tema desde diferentes ópticas con el propósito de buscar y analizar alguna alternativa que permita responder oportuna y eficazmente a las necesidades de la población en situación de desplazamiento y velar por su estabilización socioeconómica.

Por lo anterior, analizar el Programa de Generación de Ingresos -PGI- para la población desplazada, desde los aspectos considerados dentro del marco de la implementación de políticas públicas, ha permitido identificar diversas falencias que no han sido consideradas en los procesos de reorientación de la política pública. Desde este punto de vista es interesante examinar los interrogantes formulados y comprobar, de cierta forma, que los indicadores estimados para este estudio de caso ratifican que los diseñadores de la política se han preocupado más por la formulación que por los detalles de la implementación, los cuales han sido dejados a discreción de la administración pública.

Para enmarcar adecuadamente este contexto, es preciso mencionar que la fase de implementación, de acuerdo con Meny y Thoenig (1992, p. 158), es donde "[...] se generan actos y efectos a partir de un marco normativo de intenciones, de textos o discursos". Así, se puede decir que la implementación es un proceso de planeación y control o interacción y progreso de ejecutores que deben interesarse por el cumplimiento de las metas de la política pública sin que esto no garantice que el proceso se lleve a cabo sin dificultades o hacer operativas las sinergias entre las instituciones y organizaciones que discrecionalmente aplican la política. En este caso, muchas veces se deja de lado el cumplimiento de las metas y se esperan contingencias que, preferiblemente, se asumen improvisadamente, afectando la integralidad de la población objetivo y el cumplimiento de la misma política.

Desde otra perspectiva, Varela (2005) resalta que la implementación hace parte del ciclo fundamental de las políticas públicas y hace operativo el poder del Estado con el funcionamiento del aparato burocrático que ejecuta o lleva a cabo las tareas. Sin embargo, desde el enfoque organizacional, este postulado postula cinco problemas: (i) compresión o apropiación de la política pública por parte de las burocracias; (ii) comunicación con relación a los sistemas de información; (iii) organización del procesos y lidiar con el conflicto de intereses; (iv) capacidad de gestión del recurso humano; y (v) diseño organizacional. Este último pretende resolver enigmas como: ¿Qué tipo de aparato ejecuta qué política? Y, ¿qué estructura implementa qué estrategia? Según Varela (2005), 
estas controversias emergen desde el Management y se determinan como relaciones Estructura - Proceso y Estructura - Estrategia. La primera se enfoca hacia los medios y la segunda hacia los fines; una y otra están correlacionadas con la implementación en la medida que del enlace o armonización de las mismas va a depender en gran medida el éxito de la implementación de políticas públicas.

En este sentido, hasta, más o menos, 2012, los Programas de Generación de Ingresos -PGI- para la población desplazada en el marco de la Política Publica de Atención al Desplazamiento han tratado de resolver algunos aspectos socioeconómicos pero su alcance solo se ha visto temporalmente, en la medida que las evaluaciones realizadas no han permitido considerar los aspectos relevantes de cada uno de los procesos o programas desarrollados. Adicionalmente, no ha sido verídico que a partir de alguna evaluación se hayan tomado decisiones para reorientar los componentes de la Política Publica de Atención al Desplazamiento. Por lo tanto, cabe preguntarse: ¿Las deficiencias y la falta de seguimiento al Programa de Generación de Ingresos -PGI- para la población desplazada se generan por la ausencia de una evaluación económica y financiera que evidencie en forma concreta los resultados? Y, adicionalmente, ¿una efectiva evaluación permitirá contribuir en la reorientación y marcha eficiente, oportuna y efectiva de la Política Publica y de sus componentes?

Lo anterior se convierte en un problema porque existen varios actores que han contribuido o han participado en los PGI, que han vivido, tratado, reflexionado y tomado acciones efectistas - de corto plazo- para dar respuesta a situaciones particulares, y que los diseñadores de los PGI o hacedores de la política aun no han considerado para su desarrollo y impacto efectivo. Tal es el caso de las ONG (oficinas operadoras) que participan en el desarrollo de dichos programas pero como contratistas de entidades como CHF Internacional y/o Acción Social (hoy el Departamento para la Prosperidad Social).

Si bien Bogotá ha sido el gestor piloto para modelos de atención integral para este tipo de población, es de mencionar que en 1999 se puso en funcionamiento la primera Unidad de Atención y Orientación (UAO) en la localidad de Puente Aranda, llamada en esa época Unidad de Atención Integral a la Población Desplazada (UAID). En ese lugar, la Personería, la Red de Solidaridad Social, la Secretaria de Gobierno y, posteriormente, el Instituto Colombiano de Bienestar Familiar, el hospital local y otros, orientaron a los desplazados acerca de los servicios sociales y realizaron la entrega de Atención Humanitaria de Emergencia (AHE). En cierto sentido, la creación de las UAOs (posteriormente establecidas en las localidades que se consideraron como albergadoras de la mayoría de desplazados) solventó algunos aspectos de atención, pero también permitió identificar deficiencias como la falta de información sobre rutas de acceso a los diferentes derechos básicos, las fallas en el sistema de información y la demora en las entregas de AHE. 
A pesar de los documentos y la normatividad establecida en su momento para tratar de darle cumplimiento a la política pública, los cuales no surtieron el efecto esperado, la Sentencia T-025 originó en Bogotá un Plan Integral Distrital, dando espacio para la participación de los desplazados a través de comités locales y reglamentando, mediante el Decreto 117 de 2005, la participación de los mismos en el Consejo Distrital de Atención a Población Desplazada. Adicionalmente, se crearon UAO en las localidades que más albergaron población desplazada y una en la Terminal de Transporte. De esta forma, la política se "territorializó" a partir de la creación de los comités locales de atención integral a la población desplazada, adoptados por decreto local y por los planes integrales de atención local. Así mismo, se lograron entregar recursos y adelantar acciones que permitieron dar un cumplimiento parcial cuantitativo y superficialmente cualitativo de la política. Tal es el caso de los programas de generación de ingresos, los subsidios para vivienda y la ejecución del programa Familias en Acción.

Sumado a lo anterior, se llevaron a cabo las siguientes acciones:

- La Directiva de la Alcaldía Mayor 013 del 27/11/2008, en donde se establece la "Obligatoriedad de diferenciar componentes de atención a la población en situación de desplazamiento en los presupuestos de las respectivas entidades, para asegurar la efectividad de la Ley 387 de 1997, Decreto 2569 de 2000, Sentencia T-025 de 2004 y autos de seguimiento al cumplimiento de la Sentencia de la Corte Constitucional. Vigencias 2008-2012".

- Circular Conjunta Distrital del 11/03/2010, la cual solicita un "Reporte Ejecución Presupuestal Atención a Población en Situación de Desplazamiento por parte de las Entidades del Distrito Capital 2010".

Es por ello que a Bogotá se le considera como el ente territorial que ha liderado el desarrollo de la política pública, alcanzando logros respecto del goce efectivo de derechos de la población desplazada, ratificando esta afirmación mediante el balance de la política pública realizado en el marco de la sesión séptima técnica regional de seguimiento a la sentencia T-025 en enero de 2010 (Alpargatero, 2011). Los resultados destacan las siguientes propuestas que están actualmente en proceso de construcción y aprobación para su desarrollo: (i) Formulación de una política nacional de restitución y redistribución de la tierra; (ii) Reconversión de las UAO en centros de gestión social integral y de restitución de derechos; (iii) Creación de una gerencia especial para la restitución de los derechos económicos, la generación de ingresos y el empleo; (iv) La implementación de procesos de reubicación y retorno bajo el concepto de regreso a territorio seguro; y (v) Reorientación de la cuota parte de las transferencias de los municipios expulsores hacia los receptores. 
Adicionalmente, Acción Social y CHF Internacional, con la intervención de Econometría S.A., realizaron en 2008 un estudio sobre caracterización y sostenibilidad de los planes empresariales de generación de ingresos por el Convenio 082/07, en el cual se asevera, en términos generales, que: "Los negocios tienen unas ventas mensuales promedio de $\$ 1.4$ millones de pesos y la utilidad promedio mensual es aproximadamente de $\$ 400$ mil pesos" (Acción Social y CHF Internacional, 2008, p. 2); lo que puede considerarse como un análisis a priori.

Es por todo lo anterior que este tema invita a realizar un análisis particular respecto de la dinámica de los PGI, en el marco del Convenio 082 celebrado entre CHF Internacional y Acción Social durante mayo de 2007 y marzo de 2008. Teniendo esto en cuenta, este documento aplica indicadores de gestión definidos desde criterios parciales e integrales del PGI en donde, a partir de datos suministrados y la experiencia particular del equipo de investigadores, se construyen escenarios y se establecen indicadores de eficiencia, oportunidad y efectividad. De esta forma, el documento inicia con una aproximación teórica y contextual del programa en el marco de la implementación de las políticas públicas; posteriormente, se indica el proceso metodológico; luego se realiza una breve presentación del Programa de Generación de Ingresos -PGI- con algunas particularidades así como los aspectos descriptivos del caso; y, por último, se presentan los resultados de los indicadores de gestión estimados y los comentarios finales.

\section{Descripción metodológica}

Para precisar cómo se llevará a cabo este procedimiento, se establecerán varios escenarios y supuestos para analizar los datos suministrados. El motivo por el cual se establecen escenarios es porque los registros carecen de información que se puede considerar trascendental para la evaluación a realizar. Para construir cada contexto se tendrán en cuenta los elementos o aspectos propios experimentales ${ }^{1}$. De esta forma, para el criterio de eficiencia se consideraron tres (3) definiciones: una desde un enfoque o aplicabilidad económica, otra desde un enfoque o aplicabilidad a la mercadotecnia y otra desde un enfoque o aplicabilidad a la administración, respectivamente:

1. Según Andrade (2005, p. 253), la eficiencia “[...] significa utilización de los recursos de la sociedad de la manera más eficaz posible para satisfacer las necesidades y los deseos de los individuos".

2. Según el Diccionario de Marketing (1999, p. 106), la eficiencia es el "[...] nivel de logro en la realización de objetivos por parte de un organismo con el menor coste de

1 No se trata de construir supuestos sin fundamentación ni con carencia de conocimiento; por el contrario, al contar con la experiencia y prudencia de los autores respecto del tema, cada supuesto contiene los aspectos más preponderantes y los criterios que realmente se consideraron en la base de datos conformada para el Convenio 082 que desarrollaron no solo la Oficina Operadora objeto del estudio sino también otras oficinas operadoras (ONG), contratadas por CHF International, que también participaron en el desarrollo del mismo convenio. 
recursos financieros, humanos y tiempo, o con máxima consecución de los objetivos para un nivel dado de recursos (financieros, humanos, etc.)".

3. Según Koontz y Weihrich (2004, p. 14), la eficiencia es "[...] el logro de las metas con la menor cantidad de recursos".

Para este caso se concuerda con la definición del numeral 2, porque es evidente que para el Convenio 082 se destinaron unos recursos financieros con los cuales los equipos de trabajo u oficinas operadoras debían cumplir con unas metas establecidas utilizando los recursos (en este caso, financieros, profesionales, infraestructura y más) escasos, en un tiempo determinado.

Esto lleva a establecer que para calificar como eficiente, oportuno y efectivo cualquier componente del Convenio 082 respecto del PGI, el valor porcentual calculado debe estar por encima, para el caso de los criterios considerados como parciales, de $50 \%$ como situación de inicio de estabilización socioeconómica, y, para el caso de los criterios considerados como integrales, de $80 \%$ como cumplimiento del programa y como componente garante del programa adscrito a la política pública de atención al desplazado. Esto toda vez que, por tratarse de un análisis de gestión social, los resultados van más encaminados al orden social que al financiero y también porque al fin y al cabo se consideran recursos públicos que garantizan los derechos adquiridos. Claro está que existen algunas variables y aspectos no controlables dentro de la dinámica del programa que se convierten en factores críticos de éxito pero que, de fondo, permiten reorientar las estrategias, alcance y la contextualización de los ejecutores de estos programas.

Para el criterio de oportunidad se tendrán en cuenta los criterios e indicadores utilizados por Herazo y Sellamén (2010, pp. 160 - 161):

"En términos de oportunidad se tiene en cuenta el tiempo entre ayudas o entrega de recursos (Atención Humanitaria de Emergencia (AHE) y entrega del recurso correspondiente al proyecto productivo) respecto de la ruta de atención esquematizada [...]”

Para este caso, se considera oportuno el tiempo que transcurre entre el trámite administrativo de aprobación de la carta de identificación de desplazado y la remisión a la oficina operadora que otorga el recurso. Adicionalmente, se consideran los criterios propuestos por el CONPES en su Documento 3057 (1999), respecto al tema de atención de emergencia. En este sentido, se estima como oportuna a aquella atención prestada o brindada en un tiempo menor o igual a 15 días e inoportuna a aquella atención mayor o igual a 16 días calendario respecto de la remisión de la Unidad Territorial (UT) a la oficina operadora o entidad competente.

Referente al proyecto productivo, se pueden calcular dos indicadores: uno de tiempos de entrega y el otro respecto al número de participantes a quienes se les ha entregado el proyecto. En este sentido, los dos indicadores mostrarán resultados ampliamente 
inoportunos; sin embargo, se tendrá en cuenta el criterio de la ruta básica de atención. De esta forma, se considera oportuno a aquel recurso entregado en un periodo menor o igual a 16 semanas e inoportuno a aquel recurso entregado en un tiempo mayor o igual a 17 semanas, respecto del momento o la semana en la que se inicia la ruta de atención. Y para el criterio de efectividad también se tendrá en cuenta el concepto utilizado por Herazo et al. (2010), en donde mencionan que a partir de la definición asumida como la capacidad de lograr el efecto que se desea o se espera, la efectividad se considera como la observación de las actividades brindadas a los participantes del Convenio 082 durante su permanencia en el programa, teniendo en cuenta la ruta de atención establecida y los recursos otorgados, con la intención de confirmar la promoción y continuidad de los negocios o actividades de los participantes dentro del proceso denominado como estabilización socioeconómica.

\section{El programa de generación de ingresos (PGI) para el convenio 082}

Aquí se realiza una descripción breve del PGI y su ruta de atención para dar paso al análisis descriptivo con el propósito de justificar y consolidar la construcción de los escenarios y los indicadores de gestión.

\subsection{Análisis Descriptivo}

Dentro de este numeral es necesario señalar, a modo de contexto, que la estructura del programa de apoyo a la población en situación de desplazamiento utilizada para el 2007 ha sufrido cambios y que, aunque no son objeto de este estudio, deben considerarse en detalle debido a la particularidad del asunto.

Tal y como se menciona en un estudio referente al tema (Herazo et al., 2010, p. 135):

[...] la estructura del programa establecida por CHF International (referencia por su reconocimiento) para implementar el PGI dentro de lo que se denominó "Ruta Básica de Intervención del Programa" [la Ruta tiene como propósito establecer parámetros básicos, comunes y generales para la implementación del programa en cada ciudad, dejando un espacio para que los equipos locales puedan realizar adaptaciones metodológicas y pedagógicas de acuerdo con el contexto local y las características sociales y culturales de cada región o grupo poblacional por atender (Acción Social y CHF Internacional, (n.d.), p. 4)], está diseñada para que en un periodo no superior a seis meses (equivalente a más o menos 24 semanas), los participantes alcancen o empiecen una situación de estabilización socioeconómica en su nuevo lugar de residencia 
Figura 1. Estructura del Programa - Acción Social y CHF Internacional (Vigencia - 2007) Programa de Apoyo a Población en Situación de Desplazamiento

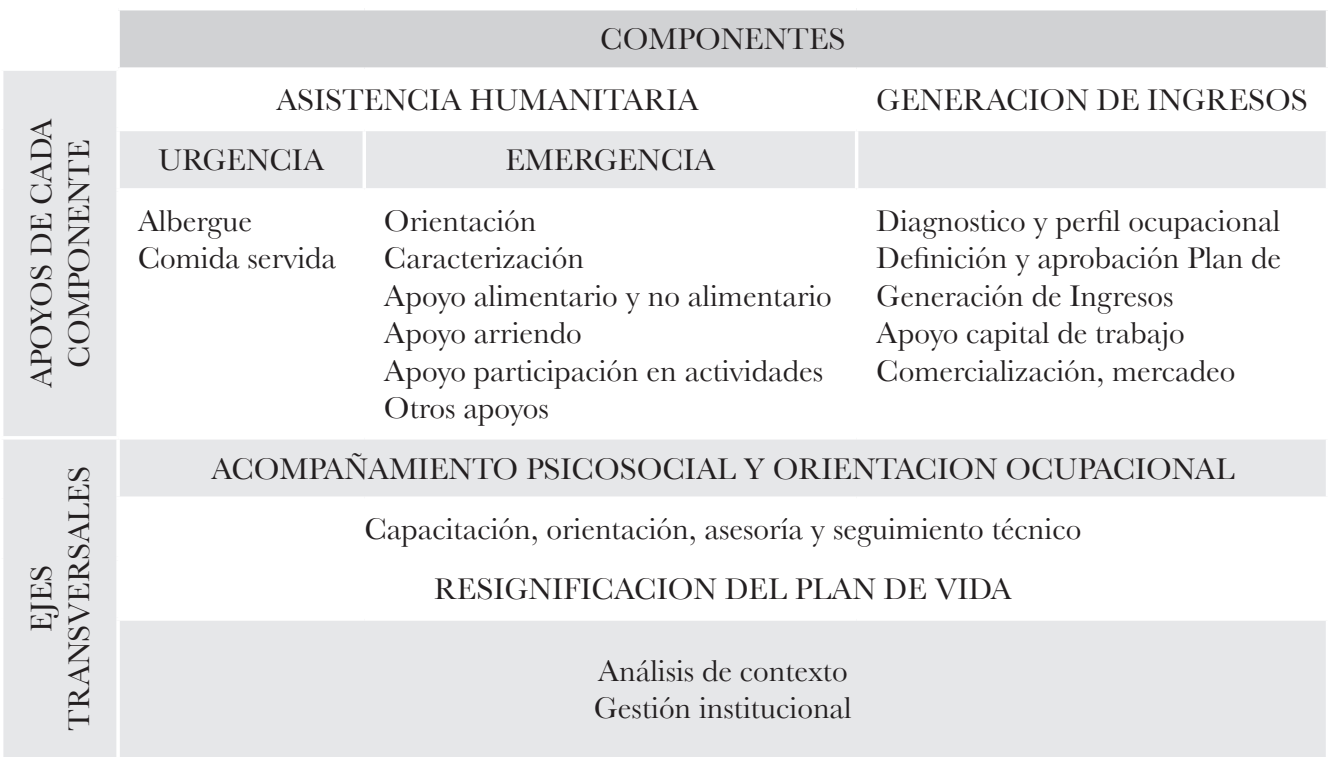

Fuente: presentación Programa de Apoyo a Población en Situación de Desplazamiento en Colombia - Convenio de Cooperación Acción Social y CHF International.

Básicamente, y teniendo en cuenta la Guía Metodológica del Programa y Operativa del mismo que se impartía a cada oficina operadora para su aplicación, el componente de Asistencia Humanitaria, para ese momento, contaba con: (i) Asistencia de urgencia o atención inmediata (apoyo alimentario y albergue temporal), dentro de este se encontraba la Asistencia Humanitaria de Emergencia (AHE): Apoyo alimentario, de higiene y de aseo, Kits de cocina y vajilla, Kits de hábitat, Kit de pañales de bebé, y Otros apoyos (expedición de documentos, auxilio funerario, etc.), la cual podía prorrogarse de acuerdo a una valoración realizada por el operador en donde se verificaba la necesidad de continuar recibiendo apoyo para subsistencia mínima.

Por su parte, el componente de Generación de Ingresos buscaba generar condiciones que les permitiera a las familias aumentar sus ingresos y una mejor calidad de vida, de forma que pudieran avanzar hacia la estabilización socio-económica. Este programa contaba con tres opciones básicas: (i) fortalecimiento empresarial, (ii) emprendimiento empresarial, y (iii) vinculación laboral. En el desarrollo de estas opciones se adelantaban acciones de acompañamiento, capacitación y gestión interinstitucional. Este proceso, que recorría todos los momentos del Programa de Apoyo a la Población en Situación de Desplazamiento, debía iniciarse desde el primer contacto del operador con el participante y estaba dirigido a toda la población vinculada al Programa. 
La ruta del Programa de Apoyo a la Población en Situación de Desplazamiento, en particular para el Convenio 082, tenía nueve momentos desde la recepción y acogida en la semana 1 hasta la semana 24. Y como se consolida, en términos generales, en el Cuadro 1, el Programa de Generación de Ingresos se desarrollaba a lo largo de todos los momentos.

\section{Cuadro 1. Características generales de los momentos del Programa de Generación de Ingresos para el Convenio 082}

\begin{tabular}{|c|c|}
\hline Momentos & Características \\
\hline $1 \mathrm{al} 4$ & $\begin{array}{l}\text { Se conocía a los participantes y se hacía una exploración ocupacional } \\
\text { inicial. }\end{array}$ \\
\hline $\begin{array}{l}\text { 5. Diagnóstico y perfil } \\
\text { ocupacional }\end{array}$ & $\begin{array}{l}\text { Se elaboraba el diagnóstico y perfil ocupacional de cada participante } \\
\text { de acuerdo con el entorno actual de desarrollo. Aquí se definía } \\
\text { si el participante pasaba directamente a la definición de planes } \\
\text { empresariales o laborales o si era necesaria su asistencia a los talleres } \\
\text { de ideas de negocios. }\end{array}$ \\
\hline $\begin{array}{l}\text { 6. Identificación y } \\
\text { aprobación de plan de } \\
\text { generación de ingresos }\end{array}$ & $\begin{array}{l}\text { Se realizaban talleres de ideas de negocios, a otros se les orientaba con } \\
\text { la formulación de su plan de generación de ingresos o para enganche } \\
\text { laboral. }\end{array}$ \\
\hline 7. Relaciones sociales & $\begin{array}{l}\text { Aquí se pretendía fortalecer las habilidades que le facilitaran y } \\
\text { mejoraran su proceso de relacionamiento, interacción y construcción } \\
\text { de redes de apoyo, mediante talleres de dinámica grupal. }\end{array}$ \\
\hline $\begin{array}{l}\text { 8. Orientación para el } \\
\text { desarrollo de los planes }\end{array}$ & $\begin{array}{l}\text { Se orientaba sobre el manejo adecuado de los recursos asignados al } \\
\text { participante en cada plan de generación de ingresos. En este parte } \\
\text { se firmaba un acta de compromiso y se entregan los recursos, que en } \\
\text { promedio ascendían a } \$ 1.400 .000 \text { pesos. }\end{array}$ \\
\hline $\begin{array}{l}\text { 9. Inicio de la consolidación } \\
\text { de los negocios o laborales }\end{array}$ & $\begin{array}{l}\text { Apoyo al participante mediante orientación administrativa, técnica, } \\
\text { capacitación, seguimiento y otros servicios complementarios (opciones } \\
\text { de crédito, acceso a otros programas, proyecciones y acciones). Este } \\
\text { momento terminaba con la graduación del participante programa en } \\
\text { la semana } 24 \text {. }\end{array}$ \\
\hline
\end{tabular}

Fuente: elaboración propia.

Los registros proporcionados nos llevan a suponer diferentes juicios en cuanto a eficiencia, oportunidad y efectividad del PGI para el Convenio 082 desarrollado por una de las oficinas operadoras ${ }^{2}$. Antes de extraer y caracterizar la información más relevante, se mencionan algunos aspectos que debieron reconocerse respecto del convenio indicado y con los cuales se hubieran determinado con más detalle los indicadores a construir: (i) Fecha de inclusión en el RUPD; (ii) Localidad en donde reside el participante; (iii) No. de

2 Es de mencionar que debido a (i) reserva estadística y (ii) derechos de autor, los autores se abstienen de mencionar el nombre de la entidad que proporcionó la información y, en adelante, se refieren a la misma como "oficina operadora" para todos los efectos. 
personas que conforman el núcleo familiar; (iv) Fechas de entrega de AHE; (v) Valores entregados de cada una de las ayudas y/o apoyos; (vi) Fecha de atención en cada momento de la ruta del programa; (vii) Fecha de aprobación de los recursos otorgados para Generación de Ingresos; (viii) Valor aprobado y otorgado para Generación de Ingresos; (ix) Fecha entrega de los recursos de Generación de Ingresos; (x) Fecha de las capacitaciones (técnicas, complementarias, etc.) brindadas; (xi) Fecha de las visitas de acompañamiento $y / o$ seguimiento a los planes de negocio (emprendimiento) y/o negocios fortalecidos; y (xii) Fecha de realización de eventos y/o acciones de acompañamiento. Cabe señalar que, con sano criterio y como se mencionó al inicio de este capítulo, algunos de los aspectos mencionados se supondrán con la mayor aproximación teniendo en cuenta el conocimiento de causa y la experiencia por parte de los autores de esta investigación.

\section{Caracterización de la Base de Datos - Convenio 082}

Conociendo la ruta metodológica y considerando que cada oficina operadora podía realizar las adaptaciones metodológicas y pedagógicas de acuerdo con el contexto local y las características sociales y culturales de cada región o grupo poblacional por atender, a modo de resumen, cada participante que era remitido a la oficina operado$\mathrm{ra}^{3}$ debía cumplir con tres (3) componentes del programa, a saber: (i) Sensibilización y Convocatoria; (ii) Formulación de Planes; y (iii) Acompañamiento y Seguimiento.

\section{Número de participantes y distribución local}

La base de datos analizada registra 3.470 participantes distribuidos de la siguiente forma: 3.464 repartidos en las diferentes localidades de Bogotá D.C. y 6 ubicados en diferentes lugares fuera de Bogotá y que no fueron atendidos por encontrarse fuera del perímetro establecido para el Convenio 082.

Cuadro 2. No. de participantes por localidad y su participación porcentual

\begin{tabular}{|l|c|c|}
\hline \multicolumn{1}{|c|}{ Localidad } & No. de Participantes & Participación \\
\hline Ciudad Bolivar & 570 & $16.5 \%$ \\
\hline Suba & 427 & $12.3 \%$ \\
\hline Bosa & 408 & $11.8 \%$ \\
\hline Kennedy & 362 & $10.5 \%$ \\
\hline San Cristobal & 317 & $9.2 \%$ \\
\hline Rafael Uribe & 270 & $7.8 \%$ \\
\hline
\end{tabular}

3 Cabe aclarar que los datos generales registrados inicialmente en el RUPD eran suministrados a las oficinas operadoras en la base de datos a diligenciar durante el desarrollo del programa y a partir de esa información se debían reportar periódicamente los indicadores o la información requerida por CHF Internacional o por Acción Social. 


\begin{tabular}{|l|c|c|}
\hline \multicolumn{1}{|c|}{ Localidad } & No. de Participantes & Participación \\
\hline Usme & 256 & $7.4 \%$ \\
\hline Engativa & 160 & $4.6 \%$ \\
\hline Tunjuelito & 128 & $3.7 \%$ \\
\hline No se puede definir & 102 & $2.9 \%$ \\
\hline Martires & 79 & $2.3 \%$ \\
\hline Santa Fe & 75 & $2.2 \%$ \\
\hline Usaquen & 74 & $2.1 \%$ \\
\hline Antonio Nariño & 61 & $1.8 \%$ \\
\hline Fontibon & 37 & $1.1 \%$ \\
\hline Barrios Unidos & 33 & $0.9 \%$ \\
\hline Candelaria & 31 & $0.9 \%$ \\
\hline Puente Aranda & 31 & $0.8 \%$ \\
\hline Chapinero & 29 & $14 \% 4$ \\
\hline Teusaquillo & & $0.9 \%$ \\
\hline
\end{tabular}

Fuente: cálculos propios a partir de la base de datos suministrada por la Oficina Operadora.

Guadro 3. No. de participantes ubicados en diferentes lugares fuera de Bogotá D.C.

\begin{tabular}{|l|c|}
\hline \multicolumn{1}{|c|}{ Otros } & No. de Participantes \\
\hline Facatativa & 2 \\
\hline Ibague & 1 \\
\hline Mosquera & 2 \\
\hline Soacha & 1 \\
\hline Total & 6 \\
\hline
\end{tabular}

Fuente: cálculos propios a partir de la base de datos suministrada por la Oficina Operadora.

Como se observa, aproximadamente $80 \%$ de los participantes se concentró en las localidades de: Ciudad Bolívar (570 participantes), Suba (427 participantes), Bosa (408 participantes), Kennedy (362 participantes), San Cristóbal (317 participantes), Rafael Uribe (270 participantes), Usme (256 participantes), Engativá (160 participantes) y Tunjuelito (128 participantes); y, aproximadamente, el 17 \% restante se ubicó en las demás localidades del Distrito. Vale la pena mencionar que, aproximadamente, hubo un $3 \%$ de 
participantes a los cuales, en principio, no se les pudo identificar su lugar de residencia y, por consiguiente, quedaron por fuera del programa.

\section{Distribución por género y edades}

Los datos registrados muestran que, de los 3.470 participantes, 1.640 son hombres y 1.830 son mujeres.

Cuadro 4. Distribución por género

\begin{tabular}{|c|c|c|}
\hline No. de Participantes & Hombres & Mujeres \\
\hline 3,470 & 1,640 & 1,830 \\
\hline Part. $(\%)$ & $47.3 \%$ & $52.7 \%$ \\
\hline
\end{tabular}

Fuente: cálculos propios a partir de la base de datos suministrada por la Oficina Operadora.

Cuadro 5. Distribución por edades

\begin{tabular}{|l|c|c|c|}
\hline Rango de Edades & Hombres & Mujeres & Totales \\
\hline Ente 18 y 25 años & 85 & 208 & 293 \\
\hline Entre 26 y 40 años & 469 & 711 & 1,180 \\
\hline Entre 41 y 60 años & 460 & 403 & 863 \\
\hline Mayores de 60 años & 132 & 60 & 192 \\
\hline Sin registro & 494 & 448 & 942 \\
\hline Totales & 1,640 & 1,830 & 3,470 \\
\hline
\end{tabular}

Fuente: cálculos propios a partir de la base de datos suministrada por la Oficina Operadora.

En este sentido, se puede apreciar que existe una mayor cantidad de mujeres participantes, por lo menos entre los 18 y los 40 años, lo que permite mencionar que una mayor proporción de mujeres son cabeza de familia. Esto se convierte en un factor crítico de éxito toda vez que cuando se establezca una unidad productiva el tiempo de dedicación a los hijos puede disminuir o, simplemente, convertir a la unidad en un negocio temporal. Sin embargo, se ha evidenciado que la mujer cabeza de familia posee una particularidad cuando se trata de asumir retos y responsabilidades al mismo tiempo.

Llama la atención que existen 942 participantes a los cuales no se les registró la edad en la base de datos, lo cual pudo ser un punto negativo a la hora de establecer estrategias de formulación y/o acompañamiento, pero más que todo se considera una falla al momento de registrar los datos. Dentro de este contexto, cabe mencionar que 221 participantes (183 hombres y 38 mujeres) cedieron el cupo a otras personas que 
probablemente también fueron desplazados pero que en la base de datos no se registra ninguna información adicional; según los registros, los motivos por los cuales estos participantes cedieron el cupo se pueden resumir en: (i) falta de tiempo, (ii) motivos laborales, (iii) reubicación, (iv) retorno, y otros aspectos que se relacionan, aparentemente, con las inconformidades del proceso.

Para iniciar el proceso, la Oficina Operadora registra a las personas que asistieron a las charlas informativas del programa. Este tipo de charlas se supone que contienen y consideran todos los aspectos relacionados con el proceso y se convierten en el espacio propicio para aclaración de dudas y para orientar adecuadamente a los participantes; 2.358 participantes asistieron a la primera charla informativa y 1.112 participantes no asistieron. No obstante, esta ausencia se debe principalmente a las personas que cedieron el cupo y a aquellos participantes que no se pudieron contactar.

\section{Componente 1 - Sensibilización y convocatoria}

En esta sección de la base de datos se registró: (i) si se realizó la primera visita domiciliaria a cada participante, (ii) la asistencia de los participantes a cuatro (4) talleres (2 psicosociales, 1 de orientación ocupacional y 1 de ideas de negocio), y (iii) si el participante aplicó a alguno de los criterios de modalidad (emprendimiento o fortalecimiento, o vinculación laboral ${ }^{4}$ ).

Guadro 6. Número de visitas domiciliarias

\begin{tabular}{|l|c|c|c|}
\hline \multicolumn{4}{|c|}{ Vistitas Domiciliarias } \\
\hline & SI & NO & Total \\
\hline No. de Participantes & 2,223 & 1,247 & 3,470 \\
\hline Participación (\%) & $64.1 \%$ & $35.9 \%$ & \\
\hline
\end{tabular}

Fuente: cálculos propios a partir de la base de datos suministrada por la Oficina Operadora.

En este sentido, se registra que se realizaron 2.223 visitas domiciliarias $(64,1 \%$ ) y que no se realizaron 1.247 visitas domiciliarias (35,9\%); estas últimas no se dieron principalmente porque fueron los casos de cesión de cupos y no ubicación o no localización de los participantes.

4 Entendido como: (i) Emprendimiento: Negocio o actividad iniciada por primera vez; (ii) Fortalecimiento: Negocio o actividad en marcha que puede consolidarse con el recurso que otorga el programa; y (iii) Vinculación laboral: inclusión a alguna empresa formal en convenio con el programa de acuerdo con las políticas de la empresa y las capacidades y habilidades del participante. 
Cuadro 7. Número de participantes que asistieron a los talleres ${ }^{5}$

\begin{tabular}{|c|c|c|c|}
\hline \multicolumn{4}{|c|}{ Asistencia a Talleres } \\
\hline & SI & NO & Total \\
\hline Taller 1 & 2,218 & 1,252 & 3,470 \\
\hline Taller 2 & 2,218 & 1,252 & 3,470 \\
\hline Taller 3 & 2,191 & 1,279 & 3,470 \\
\hline Taller 4 & 2,190 & 1,280 & 3,470 \\
\hline
\end{tabular}

Fuente: cálculos propios a partir de la base de datos suministrada por la Oficina Operadora.

Aproximadamente, $60 \%$ de la población asistió a los talleres ofrecidos y el restante $40 \%$ fueron los participantes que no se localizaron.

Cuadro 8. Modalidad determinada y aprobada para los participantes

\begin{tabular}{|l|c|c|}
\hline Modalidad Determinada & No. de participantes & Part. $(\%)$ \\
\hline Emprendimiento & 1,684 & $48.5 \%$ \\
\hline Fortalecimiento & 435 & $12.5 \%$ \\
\hline Vinculación Laboral & 11 & $0.3 \%$ \\
\hline Ninguno & 1,340 & $38.6 \%$ \\
\hline Total & 3,470 & \\
\hline
\end{tabular}

Fuente: cálculos propios a partir de la base de datos suministrada por la Oficina Operadora.

En el cuadro 8 se observa que 1.684 participantes (48,5\%) emprendieron una actividad o negocio, 435 participantes (12,5\%) ya poseían una actividad y decidieron consolidarla, 11 participantes aplicaron a la vinculación laboral $(0,3 \%)$ y para 1.340 participantes $(38,6$ \%) no se determinó ninguna modalidad para continuar con el proceso.

\section{Componente 2 - Formulación de planes}

Teniendo en cuenta las modalidades registradas para cada participante, en este punto se describirá la información, precisamente, por cada una de ellas. En primer lugar, para la modalidad de emprendimiento se tienen en cuenta los criterios de aprobación del plan de negocio, tipo de negocio, actividad económica del negocio y si el participante recibió capacitación y asesoría en la formalización del negocio. Cabe aclarar que, para efectos

5 Taller 1 - De orientación ocupacional y evaluación de competencias básicas, personales y empresariales; Taller 2 Psicosocial y desarrollo de competencias o habilidades sociales; Taller 3 - Psicosocial y desarrollo del Plan de Vida; y Taller 4 - Taller de selección de la mejor alternativa: Ideas de negocio / Preparación para el empleo. 
prácticos, se unificaron o clasificaron los negocios o actividades aprobadas para poder obtener una cuantificación unificada.

Cuadro 9. Número de negocios aprobados como emprendimiento por sector de la economía

\begin{tabular}{|l|c|c|}
\hline $\begin{array}{c}\text { Actividad Economica / } \\
\text { Sector }\end{array}$ & $\begin{array}{c}\text { No. de Negocios } \\
\text { Aprobados }\end{array}$ & Partic. $(\%)$ \\
\hline Producción & 243 & $14.4 \%$ \\
\hline Comercialización & 1,038 & $61.6 \%$ \\
\hline Servicios & 403 & $23.9 \%$ \\
\hline Totales & 1,684 & \\
\hline
\end{tabular}

Fuente: cálculos propios a partir de la base de datos suministrada por la Oficina Operadora.

En este sentido, se observa que se aprobaron 1.684 negocios o actividades ${ }^{6}$ de emprendimiento de los cuales $1.038(61,6 \%)$ se clasificaron como negocios de mera comercialización, $403(23,9 \%)$ se clasificaron como negocios que prestan algún servicio, y 243 $(14,4 \%)$ se clasificaron como negocios de producción.

En el sector de la producción sobresalieron los negocios y actividades de confecciones (donde se incluyen los procesos elaboración y comercialización) con una participación de 67,1 \% (163 negocios). Le siguen los negocios de comidas rápidas, típicas y amasijos con 20,6 \% (50 negocios), luego la producción de productos de panadería y pastelería con una participación de 4,1\% (10 negocios) y otros negocios o actividades en donde el máximo de participantes fue de 4, como carpinterías, producción de artesanías y producción de artículos de aseo. Para el sector comercial, el comercio de ropa, calzado, artesanías, entre otros y de alimentos en general ya preparados o perecederos, participaron en 48,9 \% y 48,3\% (un poco más de 500 negocios por clasificación), respectivamente; otra actividad como la comercialización de chatarra y productos reciclables participaron con 2,1\% y otras actividades en menor proporción $(0,7 \%)$.

Por su parte, para el sector de servicios el alquiler de lavadoras se convirtió en la actividad que más participó dentro del sector (48,6 \%) con 196 negocios aprobados; le siguen los servicios de belleza (que en su mayoría son a domicilio) con una participación de 12,4\% (50 unidades); los café internet, trabajos en computador, asesorías, cabinas telefónicas, fotocopiadoras e impresiones con una participación de 7,9\%; los servicios,

6 Acéptese o no, no solo para el sector analizado sino para los otros dos sectores, la gran mayoría de negocios o actividades que se aprobaban (aproximadamente $95 \%$ ) eran o son de naturaleza informal debido, principalmente, a las condiciones familiares, contextuales o a la falta de experiencia y el desconocimiento, o simplemente porque el recurso no era suficiente para alcanzar la formalidad. Adicionalmente, el sistema financiero y crediticio de la ciudad no consideraba viable y más bien riesgoso aprobar y desembolsar recursos para este grupo de personas en situación de desplazamiento. 
mantenimiento y alquiler de guadañadoras y jardinería con 6,7 \%; el servicio, alquiler y asesoría de equipos electrónicos, computadores, sonido y los servicios de ornamentación y soldadura en general con 3,5\% \% las zapaterías, sastrerías y alquiler de ropa con $3,2 \%$; y los servicios de latonería y pintura, mecánica automotriz, así como los de construcción, diseño de interiores y alquiler de maquinaria para construcción con $2,7 \%$ y 2,2 \%, respectivamente. Por último, otras actividades que corresponden a 9,2 \%. Es de mencionar que los 1.684 participantes a los cuales se les aprobó negocio o actividad recibieron capacitación y asesoría en la formalización del negocio.

Para la modalidad de fortalecimiento se aprobaron 435 planes reconocidos para su consolidación. De igual forma, se tienen en cuenta los criterios de aprobación del plan de negocio, tipo de negocio, actividad económica del negocio y si el participante recibió capacitación y asesoría en la formalización del negocio.

Aquí se observa que se aprobaron 435 negocios o actividades de fortalecimiento, de los cuales $214(49,2 \%)$ se clasificaron como negocios de mera comercialización; 128 (29,4 \%) se clasificaron como negocios de producción; y 93 (21,4\%) se clasificaron como negocios que prestan algún servicio. En el sector de la producción, sobresalieron los negocios o actividades de confecciones (donde se incluyen los procesos elaboración y comercialización) con una participación dentro de este sector de 41,4\% (53 negocios); le siguen los negocios de comidas rápidas, típicas y amasijos con 35,2 \% (45 negocios), luego la producción de artesanías con una participación de 8,6 \% (11 negocios), después los productos de panadería y pastelería con una participación de 4,7 \% (6 negocios), y otros negocios o actividades en donde el máximo de participantes fue de 4, como carpinterías.

Cuadro 10. Número de negocios aprobados como fortalecimiento por sector de la economía

\begin{tabular}{|l|c|c|}
\hline $\begin{array}{c}\text { Actividad Economica / } \\
\text { Sector }\end{array}$ & $\begin{array}{c}\text { No. de Negocios } \\
\text { Aprobados }\end{array}$ & Partic. $(\%)$ \\
\hline Producción & 128 & $29.4 \%$ \\
\hline Comercialización & 214 & $49.2 \%$ \\
\hline Servicios & 93 & $21.4 \%$ \\
\hline Totales & 435 & \\
\hline
\end{tabular}

Fuente: cálculos propios a partir de la base de datos suministrada por la Oficina Operadora.

Para el sector comercial, el comercio de alimentos en general ya preparados o perecederos participaron en 60,3 \% (129 negocios); le siguieron la comercialización de ropa, calzado, artesanías, lencería, entre otros, con una participación de 29,4% (63 negocios); y las actividades o negocios como la comercialización de chatarra, plástico reciclado, 
aluminio, cobre, eléctricos, entre otros, la comercialización de productos naturales hierbas y flores, y la comercialización de materiales para odontología participaron en $8,4 \%, 1,4 \%$ y $0,5 \%$ (18, 3 y 1 negocios), respectivamente. Por su parte, para el sector de servicios la filmación de eventos, fotografía, grabaciones, organización de eventos sociales o alquiler de rockolas participaron con 16,1 \% (15 negocios), los servicios prestados en café internet, trabajos en computador, asesorías, cabinas telefónicas, video juegos, fotocopiadoras e impresiones, mensajería, participaron con 15,1 \% (14 negocios), los servicios de salón de belleza (que en su mayoría son domicilios) participaron en $14 \%$ (13 negocios), y los servicios de reparación, comercialización de eléctricos, equipos de cómputo y celulares, alquiler y arreglo de lavadoras y servicios de lavandería, construcción, diseño de interiores, maquinaria para construcción, plomería, y otros negocios / actividades, participaron con 10,8 \%, 9,7\%, 6,5\% y $28 \%$, respectivamente.

Por último, los 435 participantes a los cuales se les aprobó negocio o actividad recibieron capacitación y asesoría en la formalización del negocio. Y para la modalidad de vinculación laboral, 11 participantes lograron vincularse a la empresa INDUASEO S.A. por medio de un contrato a término fijo por once (11) meses; sin embargo, no se registra en qué fecha se vincularon estas personas ni un detalle de las actividades realizadas durante el periodo de duración del programa y del contrato suscrito con la entidad.

\section{Componente 3 - Acompañamiento y seguimiento}

En este componente se supone que, una vez los participantes recibían el recurso aprobado bien hubiera sido para los negocios de emprendimiento como para fortalecimiento y en algunos casos para los vinculados laboralmente, los profesionales de las oficinas operadoras debían por lo menos realizarle tres (3) visitas de acompañamiento y/o seguimiento, y máximo cuatro (4) visitas a cada una de las unidades productivas o empresas en donde cada uno de los participantes se encontraban desarrollando su actividad. La idea era garantizar que los participantes tuvieran asesoría u orientación acerca de las dudas y/o de los procesos adicionales (psicosociales) que se consideraban como factores críticos de éxito para la continuidad del negocio y de su estabilización socioeconómica.

Por eso, para esta parte es necesario unificar, definir y generalizar los criterios con los cuales un participante culminaba el proceso, es decir, el estado del negocio y/o del participante al final del proceso cuando se le realizara la última visita del profesional de acompañamiento ${ }^{7}$ :

a. Activo: Negocio o actividad (emprendimiento o fortalecimiento) aprobado por el programa o participante vinculado laboralmente, que a la última visita realizada

7 Estos criterios se definen de acuerdo con la experiencia y la generalización en el manejo de los mismos en los informes entregados en su momento por los profesionales de formulación y de acompañamiento de las oficinas operadoras. 
por los profesionales de acompañamiento se encontraba en funcionamiento o ejerciendo sus labores.

b. Cambio de Negocio: Participante que decide desarrollar un negocio o actividad diferente de la inicialmente orientada, aprobada y apoyada por el programa.

c. Cierre del Negocio: Negocio o actividad que deja de funcionar y el participante decide liquidar el mismo sin ningún resultado positivo.

d. Desvío de Recursos: Participante a quien se le otorgó el recurso y que lo utiliza para gastarlo en actividades diferentes al plan de negocio orientado y aprobado.

e. En Inicio: Participante que hasta la última visita aun se encontraba en preparativos para desarrollar el plan de negocio.

f. Inactivo: Negocio o actividad que se evidencia su infraestructura pero que no presenta ningún resultado financiero y no se encuentra en ejercicio.

g. No Inicio: Participante que a la última visita realizada aun poseía el recurso y no había llevado a cabo el negocio o actividad orientada y aprobada por el programa.

h. No Localizado: Participante que durante el desarrollo del programa o de alguno de sus componentes no fue posible ubicarlo en ninguno de los números telefónicos o en las direcciones registradas.

i. No Localizado / Desvío de Recursos: Participante que realizó el proceso, se le aprobó el plan de negocio y se le desembolsó el recurso y hasta ese momento había contacto, por lo menos telefónico, y al momento de volver a contactarlo para realizarle alguna de las visitas, o no fue posible ubicarlo o sus actitudes (no contestación) evidencian el uso no adecuado del recurso.

j. Participante Fallecido: Participante que perece durante el desarrollo del programa.

k. Plan No Aprobado / No Localizado: Participante que realizó el proceso hasta el momento previo de la aprobación del plan de negocio y no fue posible localizarlo en los números telefónicos ni en la dirección registrada.

1. Plan No Aprobado / Otras Razones: Participante que realizó el proceso hasta el momento previo de la aprobación del plan de negocio y que, por cuestiones laborales o por desacuerdo con la dinámica del programa o por cuestiones de fuerza mayor (casos fortuitos) no documentados, no se le aprueba el plan de negocio. 
m. Plan No Aprobado / Reubicación: Participante que realizó el proceso hasta el momento previo de la aprobación del plan de negocio y por reubicación del mismo en otro municipio o ciudad no se le aprobó el plan de negocio.

n. Plan No Aprobado / Sin Información: Para el caso particular se infiere que hace referencia al participante que cedió el cupo previa aprobación del plan de negocio y no se registra ninguna información al respecto.

o. Retirado Temporalmente: Participante que, por cuestiones ajenas al programa, notifica su ausencia temporal y que al finalizar el programa no había reportado su regreso.

p. Retorno: Participante que regresa a su lugar de origen y aparentemente continúa su proceso en la ciudad o municipio expulsor.

q. Retorno / Desvío de Recursos: Participante que realizó el proceso, se le aprobó el plan de negocio y se le desembolsó el recurso pero en alguna de las visitas se evidenció que el recurso lo utilizó para los gastos de retorno al municipio o ciudad expulsora.

r. Reubicado: Participante que en alguna de las visitas de acompañamiento tenía su negocio activo y por cuestiones de seguridad o personales notifica su reubicación en otro municipio o ciudad con el negocio apoyado pero no se constata la veracidad de la información respecto del negocio.

s. Reubicado Activo: Participante que en alguna de las visitas de acompañamiento tenía su negocio activo y por cuestiones de seguridad o personales notifica su reubicación en otro municipio o ciudad con el negocio apoyado y periódicamente informó y envió información de resultados respecto del negocio.

t. Reubicado / Desvío de Recursos: Participante que realizó el proceso, se le aprobó el plan de negocio y se le desembolsó el recurso pero, por notificación o información de familiares o cercanos, se evidencia que hubo reubicación y el recurso otorgado se utilizó en gastos de traslado u otras necesidades.

u. Robo / Gierre Definitivo: Participante que desarrolló el proceso, poseía su negocio activo y en alguna visita de acompañamiento notifica y demuestra que ha sido víctima de robo, ya sea del recurso o de la infraestructura utilizada para el desarrollo de la actividad.

v. Sin Información: Se refiere al participante que no registra ninguna información respecto del negocio o de la actividad aprobada. 
De esta manera, a continuación se presenta la situación final de los 3.470 participantes del Convenio 082, resultado del proceso de acompañamiento y seguimiento del programa, así como el número de visitas realizadas a cada participante o negocio y si estos mismos recibieron capacitaciones de fortalecimiento o técnicas para la buena gestión del negocio.

Cuadro 11. Número de negocios / participantes y su participación (\%) por estado

\begin{tabular}{|c|c|c|}
\hline $\begin{array}{l}\text { Estado del negocio y/ } \\
\text { o del participante }\end{array}$ & no. de negocios & Part. $(\%)$ \\
\hline Activo & 1,520 & $43.80 \%$ \\
\hline Plan no aprobado / no localizado & 918 & $26.46 \%$ \\
\hline Desvio de recursos & 244 & $7.03 \%$ \\
\hline No localizado & 212 & $6.11 \%$ \\
\hline Plan no aprobado / otras razones & 119 & $3.43 \%$ \\
\hline Plan no aprobado / sin informacion & 99 & $2.85 \%$ \\
\hline Inactivo & 73 & $2.10 \%$ \\
\hline Reubicado / desvio de recursos & 67 & $1.93 \%$ \\
\hline No inicio & 47 & $1.35 \%$ \\
\hline Plan no aprobado / reubicacion & 43 & $1.24 \%$ \\
\hline No visitado & 32 & $0.92 \%$ \\
\hline Reubicado & 28 & $0.81 \%$ \\
\hline Cambio de negocio & 24 & $0.69 \%$ \\
\hline Robo / cierre definitivo & 10 & $0.29 \%$ \\
\hline Cierre del negocio & 9 & $0.26 \%$ \\
\hline No localizado / desvio de recursos & 6 & $0.17 \%$ \\
\hline Retirado temporalmente & 5 & $0.14 \%$ \\
\hline Retorno / desvio de recursos & 4 & $0.12 \%$ \\
\hline Participante fallecido & 3 & $0.09 \%$ \\
\hline Retorno & 3 & $0.09 \%$ \\
\hline En inicio & 2 & $0.06 \%$ \\
\hline Reubicado / activo & 1 & $0.03 \%$ \\
\hline Sin informacion & 1 & $0.03 \%$ \\
\hline Total & 3,470 & \\
\hline
\end{tabular}

Fuente: cálculos propios a partir de la base de datos suministrada por la Oficina Operadora. 
En términos generales y considerando los criterios definidos anteriormente, de los 3.470 participantes registrados, 43,8 \% (1.520 negocios o actividades) se registraron activos $^{8} ; 26,46 \%$ (918 planes de negocio) se registraron como planes no aprobados por imposible localización; 7,03 \% (244 participantes) utilizaron el recurso otorgado para gastos y/o necesidades diferentes al desarrollo del plan de negocio aprobado; 6,11\% (212 participantes) no fueron localizados para seguir el programa; 3,43 \% (119 participantes) no se les aprobó el plan de negocio por razones como cuestiones laborales y casos fortuitos; 2,85 \% (99 participantes) no se les aprobó el plan de negocio pero no se registra ninguna información al final del proceso; 2,10 \% (73 negocios o actividades) se registran como inactivas, lo que empieza a generar interrogantes respecto de la efectividad del programa; $1,93 \%$ (67 participantes) se reubicaron una vez fue desembolsado el recurso y lo destinaron para gastos o necesidades diferentes al desarrollo del negocio o actividad.

Conviene también distinguir la participación de los negocios o actividades no iniciados (47 unidades) 1,35\%; los planes no aprobados por reubicación de los participantes (43 unidades) equivalentes a 1,24\%; los participantes y/o negocios no visitados (32 unidades) que correspondieron a, aproximadamente, $1 \%$; y los negocios o participantes con criterios que no alcanzan a $1 \%$ como los cambios de negocio, robo, cierre definitivo, los no localizados donde se evidenció desvío de recurso, los retornos y los participantes fallecidos, entre otros.

Con más detalle, se mencionan los negocios o actividades, por separado, catalogadas como emprendimientos, fortalecimientos y vinculaciones laborales. Aquí vale la pena mencionar que los datos presentan un desajuste respecto a los participantes registrados con "cesión de cupo" debido a que, aparentemente, solamente se registró la información resultante de algún negocio que pudo o puede tener actualmente el cesionario pero no se distingue más información al respecto. Por tal razón, estos datos (aproximadamente 120 registros) no se tendrán en cuenta en esta descripción.

Para el caso de los negocios catalogados como emprendimientos, es decir, aquellos negocios en los cuales el participante ha tenido alguna intención o plan, según los datos registrados, de 1.684 negocios aprobados, 1.053 negocios se reportaron y registraron, a la última visita de acompañamiento realizada, activos (62,53\%); 213 participantes (12,65 $\%)$ se registraron con desvío de recurso; 168 participantes (9,98 \%) no se localizaron y se desconoció tanto la ubicación y situación del participante como el uso que le dio al recurso otorgado; 58 participantes $(3,44 \%)$ se reubicaron destinando los recursos otorgados para gastos y necesidades personales; 56 negocios $(3,33 \%)$ se catalogaron como inactivos; y 40 negocios $(2,38 \%)$ se registraron como no inicio.

8 Sin embargo, es pertinente mencionar que el hecho de que los negocios se consideren activos y teniendo en cuenta que, de acuerdo con la experiencia, en su mayoría (como se citó anteriormente) son negocios informales y con una consolidación incierta, no se puede aseverar ni evidenciar su permanencia en el mercado. 
Con respecto a los criterios de no visitado (25 participantes), cambio de negocio (21 negocios) y reubicaciones (18 participantes), estos participaron, respectivamente, en $1,48 \%, 1,25 \%$ y $1,07 \%$. Y los cierres de negocio, robos, cierres definitivos, no localizados con evidencia de desvío de recursos, los retornos con la misma evidencia y los participantes fallecidos, entre otros (aproximadamente 30 participantes o negocios) no alcanza a participar con el $1 \%$. Ahora, de los 1.053 negocios registrados como activos, 627 negocios o actividades, que equivalen a casi el $60 \%$, pertenecen al sector comercial, 266 negocios o actividades con una participación de aproximadamente el $25 \%$, pertenecen al sector de servicios, y 160 negocios o actividades con una participación de aproximadamente $15 \%$, pertenecen al sector productivo.

Por su parte, para los 435 negocios o actividades catalogadas como fortalecimientos se registró que 80,92 \%, 352 negocios, se encontraban activos; 6,67 \%, 29 negocios, no se localizaron; y $3,45 \%, 15$ participantes o negocios, habían desviado el uso del recurso o se encontraban inactivos. Respecto de los criterios no visitado (6 participantes o negocios), reubicado (5 participantes) y reubicado con evidencia de desvío de recursos (5 participantes), estos participaron, respectivamente, con 1,38 y 1,15\%. De resto, los cierres de negocio (2 negocios), los robos con cierre definitivo (2 negocios), cambio de negocio, no localizado con evidencia de desvío de recursos, retirado temporalmente y reubicado con evidencia de actividad en el negocio ( 1 unidad cada uno) no alcanzan a $1 \%$ de participación.

De igual modo, de los 352 negocios registrados como activos, 175 negocios o actividades, que equivalen a casi $50 \%$, pertenecen al sector comercial, 105 negocios o actividades con una participación de aproximadamente $30 \%$, pertenecen al sector productivo, y 72 negocios o actividades con una participación de aproximadamente $20 \%$, pertenecen al sector servicios. En resumen, el PGI desarrollado por la Oficina Operadora objeto de este estudio en el marco del Convenio 082, presentó los siguientes resultados cuantitativos: Se recibió una base de datos con 3.470 participantes registrados, de los cuales 2.130 (1.684 emprendimientos, 435 fortalecimientos y 11 vinculaciones laborales) recibieron la totalidad de las actividades y ayudas que otorgó el programa; y 1.416 participantes o negocios (1.053 emprendimientos, 352 fortalecimientos y 11 vinculados laboralmente), aparentemente, terminaron el programa satisfactoriamente. En términos porcentuales, el programa cumplió o fue eficiente en atención, aproximadamente, para $60 \%$ de los participantes. 


\section{Indicadores de gestión}

\subsection{Eficiencia}

Escenario 1. Eficiencia para los participantes en términos de capacitaciones, entrega de recursos y visitas de formulación y acompañamiento. En este caso se consideran los talleres ofrecidos por la Oficina Operadora en cada componente establecido. De esta forma, se cuantifican los asistentes y no asistentes calculando un porcentaje de cumplimiento (eficiencia) en términos parciales e integrales.

Cuadro 12. Eficiencia en la asistencia a las capacitaciones ofrecidas en el Componente 1

\begin{tabular}{|l|l|l|l|l|}
\hline & \multicolumn{4}{|c|}{ Componente 1 - Capacitaciones Ofrecidas } \\
\hline \multicolumn{1}{|c|}{$\begin{array}{l}\text { Criterio } \\
\text { Taller de } \\
\text { Orientación } \\
\text { Ocupacional y } \\
\text { Evaluación de } \\
\text { Competencias } \\
\text { Básicas, } \\
\text { Personales y } \\
\text { Empresariales }\end{array}$} & $\begin{array}{l}\text { Taller } \\
\text { Psicosocial y } \\
\text { Desarrollo de } \\
\text { Competencias } \\
\text { o Habilidades } \\
\text { Sociales }\end{array}$ & $\begin{array}{l}\text { Taller } \\
\text { Psicosocial y } \\
\text { Desarrollo del } \\
\text { Plan de Vida }\end{array}$ & $\begin{array}{l}\text { Taller de } \\
\text { Selección } \\
\text { de la Mejor } \\
\text { Alternativa: } \\
\text { Ideas de }\end{array}$ \\
\hline No. de Participantes & 2,218 & 2,218 & 2,191 & $\begin{array}{l}\text { Negocio / } \\
\text { Preparación } \\
\text { para el Empleo }\end{array}$ \\
\hline No. Asistieron & 1,252 & 1,252 & 1,279 & 2,190 \\
\hline Total Participantes & 3,470 & 3,470 & 3,470 & 3,470 \\
\hline \% de Cumplimiento Parcial & $63.9 \%$ & $63.9 \%$ & $63.1 \%$ & $63.1 \%$ \\
\hline \% de Cumplimiento Integral & $63.9 \%$ & $63.9 \%$ & $63.1 \%$ & $63.1 \%$ \\
\hline
\end{tabular}

Fuente: cálculos propios.

El cumplimiento o eficiencia de las capacitaciones ofrecidas en el Componente 1 respecto de la asistencia de los participantes fue, en promedio, de $63 \%$ en términos parciales como en términos integrales. Con esto y teniendo en cuenta el porcentaje establecido para esta investigación como eficiente, no quiere decir que el programa fue ineficiente pero sí es un llamado de alerta porque existen, aproximadamente, 1.300 personas en situación de desplazamiento a los cuales el Estado no les está garantizando los derechos adquiridos y, por ende, no le está dando cumplimiento a la política pública.

9 Es de mencionar que para todos los escenarios se consideran dentro del criterio parcial los participantes o negocios vigentes durante el componente; dentro del criterio integral se consideran siempre la totalidad de los participantes del Convenio 082 (3.470 participantes según base de datos). 
Cuadro 13. Eficiencia en la asistencia a las capacitaciones ofrecidas en el Componente 2 - Modalidad Emprendimiento

\begin{tabular}{|l|c|c|c|c|}
\hline \multicolumn{1}{|c|}{} & \multicolumn{5}{|c|}{ Emprendimiento } \\
\hline \multicolumn{1}{|c|}{ Criterio } & $\begin{array}{l}\text { Taller } \\
\text { Psicosocial }\end{array}$ & $\begin{array}{l}\text { Nivelación de } \\
\text { lecto-escritura } \\
\text { (Opcional) }\end{array}$ & $\begin{array}{l}\text { Taller en Gestión } \\
\text { y Manejo de } \\
\text { Unidades } \\
\text { Productivas }\end{array}$ & $\begin{array}{l}\text { Capacitación y } \\
\text { Asesoría para } \\
\text { Formular el } \\
\text { Plan de Negocio }\end{array}$ \\
\hline No. de Participantes & 1,684 & 0 & 1,684 & 1,684 \\
\hline No Asistieron & 0 & 1,684 & 0 & 0 \\
\hline Total Participantes & 1,684 & 1,684 & 1,684 & 1,684 \\
\hline$\%$ de Cumplimiento Parcial & $100.0 \%$ & $0.0 \%$ & $100.0 \%$ & $100.0 \%$ \\
\hline$\%$ de Cumplimiento Integral & $48.5 \%$ & $0.0 \%$ & $48.5 \%$ & $48.5 \%$ \\
\hline
\end{tabular}

Fuente: cálculos propios.

De este modo, para el caso del cumplimiento o eficiencia de las capacitaciones ofrecidas en el Componente 2 - Modalidad Emprendimiento, fue, en promedio, de $75 \%$ teniendo en cuenta que a la actividad denominada "Nivel de lecto-escritura", que fue opcional, no asistió ninguno de los participantes a los cuales se les aprobó el plan de negocio bajo esta modalidad (1.684). Sin embargo, por considerarse opcional se obvia y solamente se tienen en cuenta las demás; así, el porcentaje de cumplimiento en términos parciales fue de $100 \%$. Caso contrario para el cumplimiento o eficiencia en términos integrales en donde, en promedio, el porcentaje llega a, aproximadamente, $49 \%$; lo que para la evaluación integral se considera ineficiente.

Cuadro 14. Eficiencia en la asistencia a las capacitaciones ofrecidas en el Componente 2 - Modalidad Fortalecimiento

\begin{tabular}{|l|c|c|c|}
\hline \multicolumn{1}{|c|}{ Criterio } & \multicolumn{3}{|c|}{ Fortalecimiento } \\
\hline & $\begin{array}{l}\text { Taller } \\
\text { Psicosocial }\end{array}$ & $\begin{array}{l}\text { Taller en Gestión } \\
\text { para el Mejoramiento } \\
\text { de las Unidades } \\
\text { Productivas }\end{array}$ & $\begin{array}{l}\text { Capacitación y } \\
\text { Asesoría para } \\
\text { Formular el Plan } \\
\text { de Inversión }\end{array}$ \\
\hline No. de Participantes & 435 & 435 & 435 \\
\hline No Asistieron & 0 & 0 & 0 \\
\hline Total Participantes & 435 & 435 & 435 \\
\hline \% de Cumplimiento Parcial & $100.0 \%$ & $100.0 \%$ & $100.0 \%$ \\
\hline \% de Cumplimiento Integral & $12.5 \%$ & $12.5 \%$ & $12.5 \%$ \\
\hline
\end{tabular}


Para la modalidad de fortalecimiento, el promedio del cumplimiento o eficiencia de las capacitaciones ofrecidas, en términos parciales, fue de $100 \%$ y en términos integrales fue de 12,5\%; lo cual se considera, para este último criterio, ineficiente. Para la modalidad de vinculación laboral, el promedio del cumplimiento o eficiencia de las capacitaciones ofrecidas, en términos parciales, fue de $100 \%$ (ver cuadro 15).

Cuadro 15. Eficiencia en la asistencia a las capacitaciones ofrecidas en el Componente 2 - Modalidad Vinculación Laboral

\begin{tabular}{|c|c|c|c|}
\hline \multirow[b]{3}{*}{ Criterio } & \multicolumn{3}{|c|}{ Componente 2 - Capacitaciones Ofrecidas } \\
\hline & \multicolumn{3}{|c|}{ Vinculación Laboral } \\
\hline & $\begin{array}{l}\text { Taller } \\
\text { Psicosocial } \\
\text { (Actitudes } \\
\text { Laborales) }\end{array}$ & $\begin{array}{l}\text { Taller } \\
\text { Aprestamiento } \\
\text { laboral }\end{array}$ & $\begin{array}{l}\text { Talleres de } \\
\text { Formación } \\
\text { Específica o } \\
\text { Especializada }\end{array}$ \\
\hline No. de Participantes & 11 & 11 & 11 \\
\hline No Asistieron & 0 & 0 & 0 \\
\hline Total Participantes & 11 & 11 & 11 \\
\hline$\%$ de Cumplimiento Parcial & $100.0 \%$ & $100.0 \%$ & $100.0 \%$ \\
\hline$\%$ de Cumplimiento Integral & $0.3 \%$ & $0.3 \%$ & $0.3 \%$ \\
\hline
\end{tabular}

Fuente: cálculos propios.

En cambio, los porcentajes de cumplimiento o eficiencia para el Componente 3 Acompañamiento y Seguimiento de los planes formulados, y aprobados por el programa varían considerablemente. Probablemente por efectos de los tipos de negocios o actividades; sin embargo, se considera que cada capacitación se convierte en una actividad de fortalecimiento y consolidación para desarrollar cada negocio y enfrentar estratégicamente el mercado y el contexto al cual el participante afronta para su posible estabilización socioeconómica. 
Guadro 16. Eficiencia en la asistencia a las capacitaciones ofrecidas en el Componente 3 - Acompañamiento y Seguimiento

\begin{tabular}{|l|c|c|c|c|}
\hline & \multicolumn{4}{|c|}{ Componente 3 - Acompañamiento y Seguimiento } \\
\hline \multicolumn{1}{|c|}{ Criterio } & $\begin{array}{l}\text { Taller } \\
\text { psicosocial }\end{array}$ & $\begin{array}{l}\text { Talleres de } \\
\text { Fortalecimiento } \\
\text { de la Gestión } \\
\text { y Manejo de } \\
\text { Unidades } \\
\text { Productivas }\end{array}$ & $\begin{array}{l}\text { Capacitación } \\
\text { Técnica } \\
\text { Especializada }\end{array}$ & $\begin{array}{l}\text { Taller de } \\
\text { Capacitación } \\
\text { Técnica } \\
\text { Complementaria }\end{array}$ \\
\hline No. de Participantes & 2,118 & 2,118 & 214 & 137 \\
\hline No Asistieron & 12 & 12 & 1,917 & 1,994 \\
\hline Total Participantes & 2,130 & 2,130 & 2,130 & 2,130 \\
\hline \% de Cumplimiento Parcial & $99.4 \%$ & $99.4 \%$ & $10.0 \%$ & $6.4 \%$ \\
\hline \% de Cumplimiento Integral & $61.0 \%$ & $61.0 \%$ & $6.2 \%$ & $3.9 \%$ \\
\hline
\end{tabular}

Fuente: cálculos propios.

En términos parciales, el porcentaje de cumplimiento o de eficiencia para el taller psicosocial ofrecido en este componente fue de 99,4\%, lo cual manifiesta que la labor psicosocial se consolida como el eje transversal del proceso. Para el caso del taller de fortalecimiento de la gestión y manejo de las unidades productivas también este cumple o se considera eficiente con 99,4\%; caso contrario para los talleres de capacitación técnica especializada y complementaria que presentan un porcentaje de cumplimiento o eficiencia de $10 \%$ y $6,4 \%$, respectivamente; lo que significa que fueron ineficientes. Esto puede convertirse, en algún momento, como factor explicativo de la inactividad o carencia de éxito y continuidad de los negocios, pero este análisis es ajeno al objetivo de esta evaluación.

En términos integrales, los talleres mencionados anteriormente y respectivamente, presentan los siguientes porcentajes de cumplimiento o eficiencia: $61 \%$ para las dos primeras capacitaciones señaladas, 6,2 \% y 3,9 \%. Lo que se considera como ineficiente. Sin embargo, vale la pena mencionar que solamente para el Componente 2 debe considerarse que no es estadísticamente significativo evaluar por modalidad sino por componente. Lo anterior llevaría a examinar la eficiencia desde la pertinencia y contenido de cada una de las capacitaciones y su aplicabilidad en los negocios establecidos -lo cual podría evidenciarse y evaluarse en las visitas de acompañamiento- ${ }^{10}$.

10 Por no ser el objetivo de la investigación, el tema se aborda superficialmente. No se conocen con certeza ni los contenidos ni los procesos metodológicos y pedagógicos utilizados para cada una de las capacitaciones ofrecidas por la Oficina Operadora, lo cual también se considera como reserva institucional. 
Para la medición de la eficiencia de las visitas realizadas tanto para el componente de formulación y aprobación de planes y vinculaciones laborales (Componente 2), así como para el proceso de acompañamiento y seguimiento (Componente 3) del PGI, se estima que a cada negocio o participante se le realizaron las siguientes visitas: una (1) de formulación y cuatro (4) de acompañamiento. De esta forma se calcularon los porcentajes que se observan en el cuadro 17.

Cuadro 17. Eficiencia en el número de visitas realizadas para formulación y acompañamiento

\begin{tabular}{|c|c|c|c|}
\hline \multirow{2}{*}{ Criterio } & \multicolumn{3}{|c|}{ No. de Visitas } \\
\hline & Estimadas & Realizadas & Diferencia \\
\hline Inicial y de Formulación & 3,470 & 2,223 & \multirow{2}{*}{1,247} \\
\hline \% Cumplimiento Integral & \multicolumn{2}{|c|}{$64.1 \%$} & \\
\hline $\begin{array}{l}\text { Acompañamiento Parcial } \\
\text { (Negocios Formulados) }\end{array}$ & 8,520 & 2,131 & \multirow{2}{*}{6,389} \\
\hline \% Cumplimiento Parcial & \multicolumn{2}{|c|}{$25.0 \%$} & \\
\hline $\begin{array}{l}\text { Acompañamiento Integral } \\
\text { (Todos los Participantes) }\end{array}$ & 13,880 & 2,131 & \multirow{2}{*}{11,749} \\
\hline \% Cumplimiento Integral & \multicolumn{2}{|c|}{$15.4 \%$} & \\
\hline
\end{tabular}

Fuente: cálculos propios.

Para precisar cómo se obtuvieron los resultados del cuadro 17 se puede mencionar que en el proceso inicial y de formulación de los planes de negocio se debieron realizar 3.470 visitas y solamente se realizaron y registraron 2.223 visitas. Esto arroja un porcentaje de cumplimiento o eficiencia integral de 64,1\%, lo cual se cataloga como ineficiente; en el caso de las visitas de acompañamiento de los negocios formulados, como se mencionó anteriormente, se estimaron cuatro (4) visitas para cada negocio (es decir, 2.130 -emprendimientos, fortalecimientos y vinculaciones laborales- por 4) que dan un total de 8.520 visitas, de las cuales se realizaron 2.131, que dan como resultado un porcentaje de cumplimiento o eficiencia de $25 \%$; y para la estimación del acompañamiento integral se estimaron las cuatro (4) visitas para los 3.470 participantes del Convenio 082, esto arrojó la cifra de 13.880 visitas y, teniendo en cuenta que solamente para acompañamiento y seguimiento se realizaron 2.131 visitas, el porcentaje de cumplimiento o eficiencia se estima en $15,4 \%$. Para estos dos últimos resultados el cumplimiento se considera como ineficiente. 
Escenario 2. Eficiencia del programa y del otorgamiento de los recursos. Para este escenario se tendrán en cuenta las siguientes variables: (i) número de participantes registrados inicialmente para el Convenio 082 y que recibe la Oficina Operadora; (ii) el número de planes de negocio o actividades de emprendimiento y fortalecimiento, y las vinculaciones laborales aprobadas; y (iii) el número de negocios visitados satisfactoriamente durante el proceso de acompañamiento y seguimiento, es decir, los negocios que fueron visitados cuatro (4) veces de acuerdo con los criterios establecidos para tal fin. En el cuadro 18 se observan los cálculos realizados.

Cuadro 18. Eficiencia de atención del programa para el Convenio 082

\begin{tabular}{|c|c|}
$\begin{array}{c}\text { No. de Participantes } \\
\text { Registrados para el }\end{array}$ & $\begin{array}{c}\text { No. de Planes } \\
\text { de Negocio y } \\
\text { Convenio }\end{array}$ \\
$\begin{array}{c}\text { Vinculaciones } \\
\text { Laborales Aprobados }\end{array}$ \\
\hline
\end{tabular}

(1)
(2)
No. De Negocios Acompañados Satisfactoriamente (4 Visitas)
(3)

\begin{tabular}{|l|c|c|}
\hline Totales & 3,470 & 2,130 \\
\hline$\%$ Cumplimiento Parcial $(3) /(2)$ & & 7,510 \\
\hline$\%$ Cumplimiento Integral $(2) /(1)$ y $(3) /(1)$ & $61.4 \%$ & $43.5 \%$ \\
\hline
\end{tabular}

Fuente: cálculos propios.

Parcialmente y en términos de atención general el PGI, dentro del marco del Convenio 082, la Oficina Operadora cumplió o fue eficiente en 70,9 \%; es decir, a pesar de que hubo un porcentaje significativo de deserción del programa, los participantes se beneficiaron de la atención del mismo. Sin embargo, en términos integrales y como componente de la política pública de atención al desplazamiento, el programa, según los criterios establecidos, no cumplió en términos integrales en los componentes de formulación ni de acompañamiento y seguimiento. En otras palabras, el programa no garantizó los derechos de la totalidad de los ciudadanos declarados como desplazados ni cumplió con lo establecido en el decreto 2569 de diciembre 12 de 2000 (Título VII).

Y para evaluar la eficiencia en términos financieros se consideraron los participantes registrados en la base de datos del Convenio 082 (3.470 participantes) y los planes aprobados que causaron desembolso (2.119 negocios). Adicionalmente, se considera que el monto promedio que se otorgaba era de $\$ 1.400 .000^{11}$. En este sentido, se realizaron las estimaciones presupuestales de los recursos a entregar por el PGI.

11 Aunque para algunos casos y dependiendo de la decisión del Comité de Aprobación de cada oficina operadora, el monto podía sobrepasar esta suma hasta por un valor de $\$ 1.600 .000$. 
Guadro 19. Eficiencia financiera del PGI para el Convenio 082

\begin{tabular}{|c|c|c|c|c|}
\hline $\begin{array}{l}\text { Participantes y Ne- } \\
\text { gocios }\end{array}$ & $\begin{array}{c}\text { No. de } \\
\text { Participantes }\end{array}$ & $\begin{array}{c}\text { Valor Estimado } \\
\text { del Recurso a } \\
\text { Aprobar }(\$)\end{array}$ & $\begin{array}{c}\text { Valor Presupuestado } \\
\text { Total de los Recursos } \\
\text { a Entregar }(\$)\end{array}$ & $\begin{array}{c}\text { Valor Estimado } \\
\text { de los Recursos } \\
\text { Entregados }(\$)\end{array}$ \\
\hline $\begin{array}{l}\text { Registrados para el } \\
\text { Convenio }\end{array}$ & 3,470 & \multirow[t]{2}{*}{$1,400,000$} & \multirow[t]{2}{*}{$4,858,000,000$} & \multirow[t]{2}{*}{$2,966,600,000$} \\
\hline Planes Aprobados & 2,119 & & & \\
\hline \multicolumn{3}{|c|}{$\%$ Cumplimiento Parcial en terminos financieros } & $100 \%$ & \\
\hline \multicolumn{3}{|c|}{$\%$ Cumplimiento Integral en terminos financieros } & $61.1 \%$ & \\
\hline
\end{tabular}

Fuente: cálculos propios.

Los resultados parciales evidencian un $100 \%$ de cumplimiento o eficiencia y los integrales evidencian un cumplimiento de $61,1 \%$, lo cual se considera como ineficiente. En resumen, los resultados de la evaluación de eficiencia de la atención del programa así como de la estimación y otorgamiento de recursos se consolidan en el cuadro 20.

Cuadro 20. Evaluación general de eficiencia de atención y financiera del PGI - Convenio 082

\begin{tabular}{|c|c|c|c|}
\hline \multirow{3}{*}{$\begin{array}{c}\text { Eficiencia de } \\
\text { Atención }\end{array}$} & Parcial & \multicolumn{2}{|c|}{ Integral } \\
\hline & $\begin{array}{l}\text { Negocios y Vinculaciones } \\
\text { Acompañados vs. } \\
\text { Negocios y Vinculaciones } \\
\text { Aprobados }\end{array}$ & $\begin{array}{c}\text { Participantes / } \\
\text { Negocios Aprobados } \\
\text { vs. Participantes } \\
\text { Registrados en el } \\
\text { Convenio } 082\end{array}$ & $\begin{array}{c}\text { Negocios } \\
\text { Acompañados } \\
\text { vs. Participantes } \\
\text { Registrados en el } \\
\text { Convenio } 082\end{array}$ \\
\hline & $70.9 \%$ & $61.4 \%$ & $43.5 \%$ \\
\hline Criterio & EFICIENTE & \multicolumn{2}{|c|}{ INEFICIENTE } \\
\hline
\end{tabular}

\begin{tabular}{|c|c|c|}
\hline & Parcial & Integral \\
\hline \multirow{2}{*}{$\begin{array}{c}\text { Eficiencia } \\
\text { Financiera }\end{array}$} & $\begin{array}{c}\text { Estimado Recursos Entregados } \\
\text { vs. Presupuestado Negocios } \\
\text { Aprobados }\end{array}$ & $\begin{array}{c}\text { Estimado Recursos Entregados } \\
\text { vs. Presupuestado Total } \\
\text { Participantes Convenio } 082\end{array}$ \\
\hline Criterio & $100 \%$ & $61.1 \%$ \\
\hline
\end{tabular}

Fuente: cálculos propios. 


\subsection{Oportunidad}

\section{Escenario 1}

Tiempo entre la visita de formulación del plan de negocios y la entrega del recurso para el desarrollo del negocio o actividad de acuerdo con la ruta de atención. Para la construcción de este escenario se tendrá en cuenta que:

- La fecha en la cual se dio inicio al Convenio 082 fue mayo de 2007 -para trabajar con fechas especificas se considerará a partir del 1 de junio de 2007-12.

- Asumiendo que los 4 o 5 momentos de la misma se cumplan eficientemente como se establece; en este sentido se supone que las visitas de formulación iniciaron en el mes de julio de 2007.

- La capacidad de contratación de los profesionales de formulación era de quince (15) profesionales y que cada uno, semanalmente (lunes a viernes), era $100 \%$ eficiente y realizaba 30 visitas para un promedio de 6 visitas diarias.

- Se consideran únicamente los negocios aprobados para las modalidades de emprendimiento y fortalecimiento, es decir, 2.119 unidades productivas.

- Se realizaban cuatro Comités de Aprobación ${ }^{13}$ de los planes de negocio cada mes, teniendo en cuenta su dinámica administrativa y operativa posterior ${ }^{14}$, según la ruta metodológica de las semanas 7 y 8.

Este escenario se puede observar más fácilmente en el cuadro 21 y 22:

12 Se asume que el Convenio 082 inició el 1 de mayo de 2007 y finalizó el 31 de marzo de 2008. Sin embargo y considerando los procesos administrativos y logísticos por parte de la oficina operadora (aspectos formales y de selección y contratación del personal), se asume que no hubo mayores retrasos en las formalizaciones y adecuaciones de las instalaciones y, a su vez, se contrató a todo el personal en máximo 30 días calendario. Por esto se da un espacio hasta el 1 de junio como fecha de inicio del programa.

13 Estos comités, normalmente y para garantizar una adecuada gestión y aprobación, se realizaban después de realizar los talleres respectivos (estos talleres se desarrollaban en aproximadamente una semana); estaban presididos por un grupo máximo de 5 profesionales acompañados de los coordinadores de área y/o el coordinador o director del programa de la oficina operadora, los cuales presentaban, aproximadamente, entre 50 y 70 planes de negocio cada uno (resultantes de las visitas realizadas en dos semanas de trabajo, es decir en 10 o 12 días de trabajo, y de los talleres realizados que en promedio, por grupo de profesionales, se dedicaban de uno a tres días para este proceso).

14 Dado que una vez se aprobaban los planes se procedía a tramitar los desembolsos (que se realizaban mediante cheques girados a cada participante) para que en una jornada (un día) se entregaran. Dentro de este contexto debe considerarse que cada comité duraba aproximadamente 1 día de trabajo, por lo que, para un número de 20 profesionales, se gastaban 4 días y para la entrega del recurso se dedicaba un día. 
Cuadro 21. Proyección de visitas de formulación por profesional contratado

\begin{tabular}{|l|c|c|}
\hline \multicolumn{2}{|c|}{ No. de Profesionales de Formulación Contratados } & 15 \\
\hline Criterio & Por Profesional & Todos (15) \\
\hline Visitas Diarias en Promedio & 6 & 90 \\
\hline Visitas Semanales & 30 & 450 \\
\hline Visitas Quincenales & 60 & 900 \\
\hline Visitas Mensuales & 120 & 1,800 \\
\hline
\end{tabular}

Fuente: elaboración propia.

Cuadro 22. Estimación de visitas y fechas de formulación y aprobación de planes de negocio

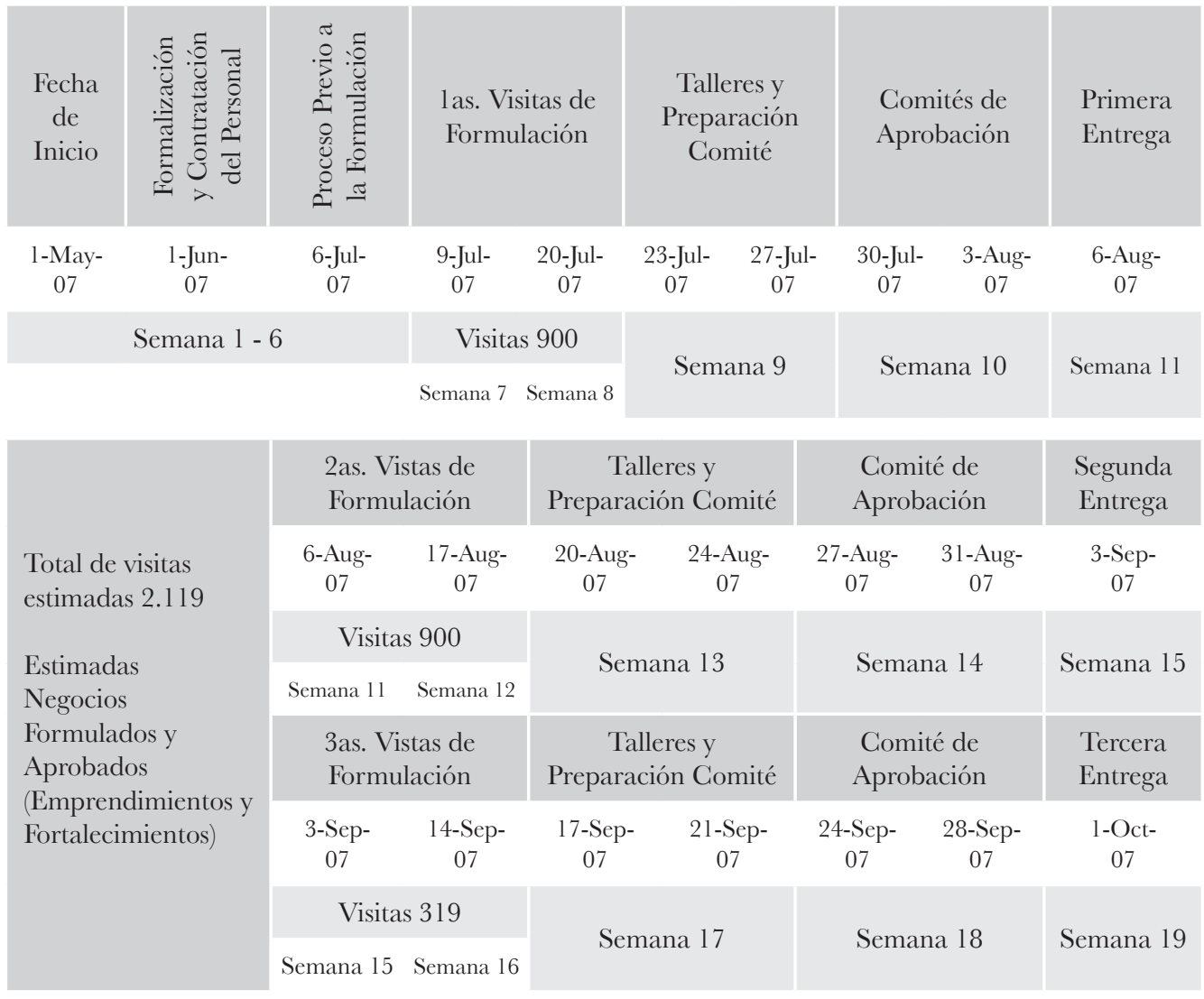

Fuente: elaboración propia.

Se dice que el 1 de mayo de 2007 inició el Convenio 082. La formalización y contratación del personal estaba lista el 1 de junio y al 6 de julio ya habían transcurrido, según la ruta metodológica, sin problemas y con la mayor eficiencia, los cinco (5) primeros 
momentos. En este sentido, a partir del 9 de julio (semana 7) se dio el inicio a las visitas de formulación hasta el 20 de julio y se cumple de acuerdo con lo estimado en el cuadro 22. Así, los mismos profesionales de formulación preparan y realizan los talleres correspondientes y elaboran los respectivos documentos para el comité que se realiza durante la semana 10 (estimando, como se mencionó, 1 comité por día). Por último, se prepara la entrega para realizarla el día 6 de agosto en la semana 11, tal y como se establece en la ruta.

Pero solamente se está haciendo mención a 900 planes de negocio visitados formulados, aprobados y con recursos entregados ${ }^{15}$, a los cuales se les cataloga como oportunos porque se encuentran dentro del tiempo establecido en la ruta de atención; en este escenario aun hacen falta 1.219 participantes por visitar, formular, aprobar y entregarles el recurso. Lo preocupante es que ya para el segundo y tercer grupo de personas a realizarles el proceso, este se cataloga como inoportuno ${ }^{16}$.

En términos de días o en términos parciales, aproximadamente en 28 días después de la visita de formulación se le está entregando el recurso al participante, lo cual se considera oportuno (tanto para las primeras, segundas y terceras visitas, según cuadro 22); sin embargo, en términos integrales el programa es inoportuno porque todos los participantes inician en el mismo momento y para los visitados en agosto o septiembre la inoportunidad puede verse afectada por las necesidades básicas.

\section{Escenario 2}

Tiempo entre visitas de acompañamiento. Aquí se debe dar continuidad al escenario anterior debido a que el proceso de acompañamiento y seguimiento depende del proceso de formulación. De esta forma, se consideran los mismos supuestos más los siguientes:

- Se realizan, en total, 4 visitas de acompañamiento a todos los negocios aprobados (con la misma dinámica de los profesionales: 6 visitas diarias cada uno, teniendo en cuenta que se contratan 10 profesionales más $\left.{ }^{17}\right)$.

15 Aquí la oficina operadora empieza a sobrellevar las particularidades del programa porque se supone que posterior a la entrega de los recursos, para darle continuidad al proceso, los mismos profesionales de formulación eran los que visitaban los negocios durante el proceso de acompañamiento, pero teniendo en cuenta que en esos momentos no se había cumplido la meta de visitas y planes de negocios (aparte de las demás actividades pedagógicas y administrativas), la prioridad era el proceso de formulación.

16 Y cabe mencionar que no se están considerando las visitas fallidas, es decir, los participantes que no se encontraban o que en algún momento dejaban esperando a los profesionales.

17 Aunque a veces, por el tiempo a cumplir en la ruta, los términos del Convenio y algunos profesionales que renunciaban, se seleccionaban (en el menor tiempo posible) y contrataban profesionales de acompañamiento con otras condiciones laborales para apoyar el proceso. 
- Se considera oportuno un espacio de, por lo menos, 15 días calendario entre visitas con el propósito de observar una evolución adecuada y poder ofrecer las capacitaciones adecuadas y planear y realizar acciones estratégicas, aparentemente, para que los participantes y negocios no desviaran sus recursos y no entraran en inactividad o cierre del mismo.

Nuevamente se menciona que por capacidad de contratación, para el programa, el proceso de acompañamiento y seguimiento se convierte, inicialmente, en una actividad confusa porque los profesionales socioeconómicos aun se encuentran en el proceso de formulación como se observa en el cuadro 22. No obstante, el proceso empieza a asimilarse pero aproximadamente hasta la semana 15 o 16, sabiendo que ya existe inoportunidad y los profesionales debían actuar estratégicamente para cumplir con la meta de cuatro (4) visitas por negocios antes de la semana 24, según la ruta de atención ${ }^{18}$.

Además, se considera que para las terceras visitas de formulación, en donde solamente faltaban 319 participantes por formular de los 2.119, estos los formularon solo 5 profesionales en dos semanas; el resto (10 profesionales) empezaron a realizar las visitas de acompañamiento de sus participantes formulados más otros 10 profesionales contratados para la labor. Dicho esto, en el cuadro 23 se observa la proyección de las visitas de acompañamiento.

Cuadro 23. Estimación de visitas y fechas de acompañamiento y seguimiento

\begin{tabular}{|c|c|}
\hline \multicolumn{2}{|c|}{$\begin{array}{c}\text { las. Vistas de } \\
\text { Acompañamiento }\end{array}$} \\
\hline 3-Sep-07 & 14-Sep-07 \\
\hline \multicolumn{2}{|c|}{ Visitas 1,200} \\
\hline $\begin{array}{c}\text { Semana } \\
15\end{array}$ & $\begin{array}{c}\text { Semana } \\
16\end{array}$ \\
\hline 17-Sep-07 & 28-Sep-07 \\
\hline \multicolumn{2}{|c|}{ Visitas 930} \\
\hline $\begin{array}{c}\text { Semana } \\
17\end{array}$ & $\begin{array}{c}\text { Semana } \\
18\end{array}$ \\
\hline $\begin{array}{r}\text { Total } \\
2,\end{array}$ & $\begin{array}{l}\text { itados } \\
0\end{array}$ \\
\hline
\end{tabular}

\begin{tabular}{|c|c|}
\hline \multicolumn{2}{|c|}{ 2as. Vistas de } \\
Acompañamiento \\
\hline 1-Oct-07 & 12 -Oct-07 \\
\hline Visitas & 1,500 \\
\hline $\begin{array}{cc}\text { Semana } \\
19\end{array}$ & $\begin{array}{c}\text { Semana } \\
20\end{array}$ \\
\hline 15-Oct-07 & $26-$ Oct-07 \\
\hline Visitas & 630 \\
\hline Semana & Semana \\
21 & 22 \\
\hline Total Visitados \\
2,130
\end{tabular}

\begin{tabular}{|cc|}
\hline \multicolumn{2}{|c|}{ 3as. Vistas de } \\
Acompañamiento
\end{tabular}

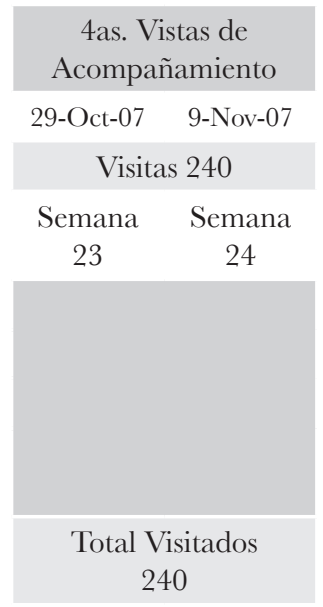

Fuente: elaboración propia.

18 A estas alturas y en aras de cumplir con lo establecido en la ruta metodológica y en el Convenio 082, en términos generales, muchas veces las visitas de acompañamiento se enfocaban en los negocios que los profesionales consideraban exitosos, es decir, aquellos que contaban con una infraestructura definida y, por lo menos, ya estaban produciendo y/o vendiendo y/o prestando el servicio, recibiendo ingresos para subsistir. Por esta razón, el tiempo entre visitas a veces no daba opción para evidenciar la evolución de los negocios. 
Es evidente entonces, la oportunidad para aproximadamente la mitad de los negocios aprobados y la inoportunidad para el resto de las visitas de acompañamiento en este escenario. Pero también se convierte en un escenario ficticio - pero con el que se solía trabajar-, en primer lugar, porque no es posible cumplir adecuadamente con las cuatro (4) visitas así se consideren los desvíos de recursos, reubicaciones, no localizaciones, entre otras, debido al tiempo establecido en la ruta; sin embargo y como el Convenio iba hasta marzo de 2008, probablemente se idearon estrategias para cumplir con la meta de visitas establecida.

Tampoco se puede dejar de lado que hubo, probablemente, negocios que fueron visitados las 4 veces pero haciendo énfasis a los negocios que, por criterio del profesional, valía la pena realizarle el proceso completo. No obstante, quedan en el tintero las capacitaciones y talleres desarrollados como fortalecimientos porque no se conocen ni las metodologías, ni los procesos pedagógicos, ni las fechas en que se realizaron, por no ser objeto de estudio para este caso.

\section{Escenario 3}

Tiempo de duración del programa respecto del estado final del negocio y de los participantes. Teniendo en cuenta lo mencionado, es indiscutible la inoportunidad del programa, pero para efectos cuantitativos y cualitativos se menciona lo siguiente:

- En términos parciales, es decir, sobre los 2.130 negocios y vinculaciones laborales aprobadas se estimó un porcentaje de oportunidad de 66,5\% y un porcentaje de inoportunidad de $33,5 \%$.

- En términos integrales, es decir, respecto de la totalidad de los participantes del Convenio 082 se estimó un porcentaje de oportunidad de 61,4\% y un porcentaje de inoportunidad de 38,6\%.

Entonces, se interpreta que el programa en términos parciales es oportuno y en términos integrales es inoportuno.

Cuadro 24. Oportunidad e inoportunidad parcial del PGI

\begin{tabular}{|c|c|c|c|c|c|}
\hline $\begin{array}{c}\text { Negocios } \\
\text { Formulados }\end{array}$ & No. & $\begin{array}{l}\text { Negocios reportados } \\
\text { como "Activos" al } \\
\text { final del programa }\end{array}$ & Diferencia & $\begin{array}{l}\text { Porcentaje de } \\
\text { Oportunidad }\end{array}$ & $\begin{array}{l}\text { Porcentaje de } \\
\text { Inoportunidad }\end{array}$ \\
\hline & (1) & (2) & (3) & $(2) /(1)$ & $(3) /(1)$ \\
\hline Emprendimiento & 1,684 & 1,053 & 631 & $62.5 \%$ & $37.5 \%$ \\
\hline Fortalecimiento & 435 & 352 & 83 & $80.9 \%$ & $19.1 \%$ \\
\hline Vinculación Laboral & 11 & 11 & 0 & $100.0 \%$ & $0.0 \%$ \\
\hline Totales & 2,130 & 1,416 & 714 & $66.5 \%$ & $33.5 \%$ \\
\hline
\end{tabular}


Guadro 25. Oportunidad e inoportunidad integral del PGI

\begin{tabular}{|c|c|c|c|}
\hline \multirow[t]{2}{*}{ Criterio } & \multirow[t]{2}{*}{ No. } & $\begin{array}{l}\text { Porcentaje de } \\
\text { Oportunidad }\end{array}$ & $\begin{array}{l}\text { Porcentaje de } \\
\text { Inoportunidad }\end{array}$ \\
\hline & & $(2) /(1)$ & $(3) /(1)$ \\
\hline (1) Participantes Registrados Convenio & 3,470 & \multirow{3}{*}{$61.4 \%$} & \multirow{3}{*}{$38.6 \%$} \\
\hline (2) Negocios y Vinculaciones Aprobadas & 2,130 & & \\
\hline (3) Participantes No Atendidos & 1,340 & & \\
\hline
\end{tabular}

Fuente: cálculos propios.

\subsection{Efectividad}

\section{Escenario 1}

Permanencia y estabilidad de los negocios. Según Acción Social (Hoy Departamento para la Prosperidad Social), el Programa de Generación de Ingresos -PGI- es un:

"Proceso que complementa los esfuerzos del Estado, de las organizaciones privadas y de la cooperación internacional para contribuir a la superación de la pobreza de las familias vulnerables y desplazadas a través de actividades sociales, económicas y ambientales viables y sostenibles, que reconozcan la diversidad cultural y que promuevan el mejoramiento de los ingresos lícitos, la conformación progresiva de redes productivas, el autoconsumo, el fortalecimiento de las capacidades de las personas y el aseguramiento de sus activos." (obtenida del sitio http://www.accionsocial.gov.co/contenido/contenido.aspx?catID=252\&conID=179, el 28 de noviembre de 2011)

Se aclara esto porque, de esta forma, se puede interpretar que el Programa de Generación de Ingresos, para los participantes del Convenio 082, debía contribuir a la superación de la pobreza mediante actividades productivas con el propósito de iniciar un proceso de estabilización socioeconómica (como se mencionó anteriormente a lo que establece el Decreto 2569 de diciembre 12 de 2000 -específicamente, en el Título VII haciendo énfasis en los Artículos 25 y 26- como reglamentario de la Ley 387 de 1997). De ahí que el programa debía ser efectivo y garantizar, por lo menos, la permanencia de las actividades aprobadas y apoyadas y su sostenibilidad en el "mercado"19.

En este orden de ideas y teniendo en cuenta las fechas de entrega de los recursos y la fecha estimada en la cual se termina el programa (semana 24), con cada estado del

19 La economía de mercado a la cual pertenecen la gran mayoría de estos negocios es a la informal y esto, en términos de crecimiento y desarrollo sectorial, no contribuye adecuadamente. En términos parciales, es decir, de cada participante, el programa generó y fortaleció las economías de subsistencia que no le apuntaron a la garantía de los derechos adquiridos como ciudadano y como desplazado. 
negocio o actividad se puede determinar un porcentaje de efectividad parcial e integral del programa, solamente para los negocios considerados como activos y para los participantes que se vincularon laboralmente -aunque solo sea por once (11) meses-.

Cuadro 26. Fechas estimadas de entrega de recursos y terminación según la ruta del programa

\begin{tabular}{|c|c|c|}
\hline $\begin{array}{c}\text { Entrega } \\
\text { Estimada }\end{array}$ & $\begin{array}{c}\text { Fecha estimada de entrega } \\
\text { de los recursos }\end{array}$ & $\begin{array}{c}\text { Fecha estimada de } \\
\text { terminación del programa }\end{array}$ \\
\hline Primera & 6 de Agos de 2007 & Semana 24 \\
\hline Segunda & 3 de Sep de 2007 & 9 de Nov de 2007 \\
\hline Tercera & 1 de Oct de 2007 & \\
\hline
\end{tabular}

Fuente: cálculos propios.

Cuadro 27. Efectividad parcial e integral del PGI para el Convenio 082

\begin{tabular}{|l|c|c|c|}
\hline $\begin{array}{c}\text { Estado de los } \\
\text { Negocios }\end{array}$ & No. & $\begin{array}{c}\text { Porcentaje de } \\
\text { Efectividad Parcial } \\
\text { del Programa }\end{array}$ & $\begin{array}{c}\text { Porcentaje de } \\
\text { Efectividad Integral } \\
\text { del Programa }\end{array}$ \\
\hline Activos & 1,416 & $66.5 \%$ & \\
\hline Los Demás & 714 & $33.5 \%$ & $40.8 \%$ \\
\hline Total & 2,130 & & \\
\hline $\begin{array}{l}\text { Total Participantes } \\
\text { del Convenio }\end{array}$ & 3,470 & & \\
\hline
\end{tabular}

Fuente: cálculos propios.

Los porcentajes de efectividad parciales estimados para los negocios activos (poniendo en duda su permanencia en el mercado debido a que la mayoría son negocios informales con una consolidación incierta) y para los demás (es decir, todos aquellos considerados con los criterios de culminación del proceso diferente del activo), respectivamente, son de 66,5 \% y 33,5\%. Estos resultados establecen que el programa, aparentemente, fue efectivo para 1.416 negocios. Y para el caso del porcentaje integral calculado respecto de los negocios activos versus la totalidad de los participantes registrados en el Convenio inicialmente es de 40,8 \%, lo que cataloga al programa como inefectivo. En pocas palabras, para casi el $40 \%$ de los participantes las visitas, capacitaciones y demás apoyos y estrategias brindadas u orientadas por los profesionales de la oficina operadora fueron inútiles. 


\section{Escenario 2}

Efectividad de las visitas de acompañamiento realizadas vs. los negocios que dejaron de funcionar.

Para este caso se asumirán de los 2.119 planes aprobados y apoyados por el programa; es decir, de los 1.684 negocios de emprendimiento y los 435 negocios de fortalecimiento, los negocios catalogados como: Cierre de Negocio, En Inicio, Inactivo, No Inicio, Robo / Cierre Definitivo.

Cuadro 28. Número de visitas de acompañamiento realizadas

a los negocios que dejaron de funcionar

\begin{tabular}{|c|c|c|c|c|c|}
\hline \multirow{2}{*}{ Estado del Negocio } & \multicolumn{4}{|c|}{ No. de Visitas Realizadas } & \multirow{2}{*}{ Total } \\
\hline & 1 & 2 & 3 & 4 & \\
\hline Cierre de Negocio & & 2 & 2 & 5 & 9 \\
\hline En Inicio & & & & 2 & 2 \\
\hline Inactivo & 3 & 7 & 10 & 51 & 71 \\
\hline No Inicio & & 6 & 6 & 28 & 40 \\
\hline Robo / Cierre Definitivo & 3 & 3 & & 3 & 9 \\
\hline Totales & 6 & 18 & 18 & 89 & 131 \\
\hline
\end{tabular}

Fuente: cálculos propios.

Este escenario puede convertirse en tema de discusión debido a que, tanto en términos parciales como integrales, es inefectivo. Y la cuestión es porque en este aspecto se puede entrar a considerar lo cualitativo, es decir, la efectividad en la labor de los profesionales (conocimiento del contexto, orientación adecuada, visita oportuna, formulación adecuada), por una parte, y, por otra, las variables no controlables del programa (como la dinámica contextual -en todo sentido- de las localidades en donde se ubicaban los participantes vs. sus costumbres natales). Entonces, se puede cuestionar que, por ejemplo, si a 51 negocios/participantes se les realizó 4 visitas, ¿qué pudo haber fallado o qué se dejó de hacer para que los negocios continuaran en esta situación? Lo mismo podría preguntarse para los negocios que no iniciaron.

En términos de la evaluación, el porcentaje de efectividad parcial estimado para los 131 negocios que dejaron de funcionar y que en algún momento fueron visitados por los profesionales de acompañamiento fue de 6,2\% (inefectivo); y el porcentaje de efectividad integral calculado fue de 3,8 \% (inefectivo). Es decir, para estos negocios/participantes las visitas de acompañamiento fueron totalmente inefectivas. 


\section{Escenario 3}

Inefectividad del programa respecto de la ubicación, condición y satisfacción de las necesidades básicas de los participantes. Con este último escenario se pretende evidenciar la inefectividad del programa respecto del seguimiento a los participantes y la persistencia de los mismos, teniendo en cuenta que esto se convierte en un aspecto no controlable por la oficina operadora pero que tiene que ver con el sistema de registro ${ }^{20}$ y las condiciones socioeconómicas, contextuales del lugar de residencia, familiares, psicosociales y hasta institucionales. Lo anterior, para efectos de la evaluación, se considera como Inhibición o Deserción y No Atendidos / Cesión de Cupo ${ }^{21}$.

\section{Guadro 29. Inhibición o Deserción y No Atendidos / Cesión} de Cupo Participaciones (\%) Parciales e Integral

\begin{tabular}{|l|l|l|l|l|l|}
\hline $\begin{array}{l}\text { Participantes } \\
\text { Convenio 082 }\end{array}$ & 1,684 & 435 & 11 & 1,340 & 3,470 \\
\hline
\end{tabular}

\begin{tabular}{|c|c|c|c|c|c|c|c|}
\hline Criterios & $\begin{array}{l}\text { Formulados } \\
\text { y Aprobados } \\
\text { Emprendi- } \\
\text { miento }\end{array}$ & $\begin{array}{l}\text { Formulados } \\
\text { y Aprobados } \\
\text { Fortaleci- } \\
\text { miento }\end{array}$ & $\begin{array}{l}\text { Vincu- } \\
\text { laciones } \\
\text { Laborales }\end{array}$ & $\begin{array}{c}\text { No } \\
\text { Atendidos } \\
\text { / Cesión de } \\
\text { Cupo }\end{array}$ & Totales & $\begin{array}{c}\text { Part. }(\%) \\
\text { Parcial }\end{array}$ & $\begin{array}{c}\text { Part. }(\%) \\
\text { Integral }\end{array}$ \\
\hline $\begin{array}{l}\text { Desvío de } \\
\text { Recursos }\end{array}$ & 213 & 15 & $\begin{array}{c}\text { No } \\
\text { Aplica }\end{array}$ & 16 & 244 & $14.0 \%$ & $7.0 \%$ \\
\hline No Localizado & 168 & 29 & & 15 & 212 & $12.2 \%$ & $6.1 \%$ \\
\hline $\begin{array}{l}\text { No Localizado } \\
\text { / Desvío de } \\
\text { Recursos }\end{array}$ & 5 & 1 & & 0 & 6 & $0.3 \%$ & $0.2 \%$ \\
\hline No Visitado & 25 & 6 & & 0 & 31 & $1.8 \%$ & $0.9 \%$ \\
\hline $\begin{array}{l}\text { Plan No } \\
\text { Aprobado / No } \\
\text { Localización }\end{array}$ & 0 & 0 & & 918 & 918 & $52.7 \%$ & $26.5 \%$ \\
\hline $\begin{array}{l}\text { Plan No } \\
\text { Aprobado / } \\
\text { Otras Razones }\end{array}$ & 0 & 0 & & 119 & 119 & $6.8 \%$ & $3.4 \%$ \\
\hline
\end{tabular}

20 En ese momento hubo evidencias de: (i) Las falencias del sistema de registro estatal (RUPD) pero la oficina operadora no tenia ni voz ni voto en este proceso, solamente el intermediario era el contratante de la ONG (en este caso CHF Internacional); (ii) Las condiciones de hacinamiento de algunas familias; (iii) La entera desubicación de los participantes en Bogotá; (iv) Las condiciones precarias de vivienda y manutención de algunos participantes; (v) El desconocimiento contextual por parte de las instituciones y de los diseñadores del programa; y (vi) La condición de no desplazado de algunos participantes pero que por estar registrados en el sistema se debían atender; entre otros.

21 Como se mencionó anteriormente, las Cesiones de Cupo se registran como tal en la base de datos pero se carece de conocimiento dentro de la dinámica del programa y tampoco existe documentación o información registrada de los cesionarios dentro de la base de datos, solamente la del estado final del negocio. Para efectos de la evaluación, solo se consideran estos en este escenario pero únicamente dentro los criterios considerados. 
ISSN: 0124-3551 / Año 17, No 26 / enero-junio / pp. 175-218

\begin{tabular}{|c|c|c|c|c|c|c|c|}
\hline Criterios & $\begin{array}{l}\text { Formulados } \\
\text { y Aprobados } \\
\text { Emprendi- } \\
\text { miento }\end{array}$ & $\begin{array}{c}\text { Formulados } \\
\text { y Aprobados } \\
\text { Fortaleci- } \\
\text { miento }\end{array}$ & $\begin{array}{l}\text { Vincu- } \\
\text { laciones } \\
\text { Laborales }\end{array}$ & $\begin{array}{c}\text { No } \\
\text { Atendidos } \\
\text { / Cesión de } \\
\text { Cupo }\end{array}$ & Totales & $\begin{array}{c}\text { Part. }(\%) \\
\text { Parcial }\end{array}$ & $\begin{array}{c}\text { Part. }(\%) \\
\text { Integral }\end{array}$ \\
\hline $\begin{array}{l}\text { Plan No } \\
\text { Aprobado / } \\
\text { Reubicación }\end{array}$ & 0 & 0 & & 43 & 43 & $2.5 \%$ & $1.2 \%$ \\
\hline $\begin{array}{l}\text { Plan No } \\
\text { Aprobado } \\
\text { / Sin } \\
\text { Información }\end{array}$ & 0 & 0 & & 99 & 99 & $5.7 \%$ & $2.9 \%$ \\
\hline $\begin{array}{l}\text { Retorno / } \\
\text { Desvío de } \\
\text { Recursos }\end{array}$ & 4 & 0 & & 0 & 4 & $0.2 \%$ & $0.1 \%$ \\
\hline $\begin{array}{l}\text { Reubicado } \\
\text { / Desvío de } \\
\text { Recursos }\end{array}$ & 58 & 5 & & 4 & 67 & $3.8 \%$ & $1.9 \%$ \\
\hline Total & 473 & 56 & 0 & 1,214 & 1,743 & & \\
\hline
\end{tabular}

Cuadro 30. Inefectividad del PGI - Convenio 082

\begin{tabular}{|c|c|c|}
\hline \multirow{2}{*}{ Criterio } & \multicolumn{2}{|c|}{ Porcentaje de Inefectividad del Programa } \\
\hline & Parcial & Integral \\
\hline $\begin{array}{l}\text { Inhibicion o Deserción de los Negocios } \\
\text { Aprobados (1) }\end{array}$ & $25.0 \%$ & $15.2 \%$ \\
\hline No Atendidos / Cesión de Cupos (2) & $90.6 \%$ & $35.0 \%$ \\
\hline
\end{tabular}

Inhibicion o Deserción y No Atendidos/Cesión Total (1) + (2) 50.2%

Fuente: cálculos propios. 
Como se observa, los cálculos indican la inefectividad del programa en aproximadamente $50 \%$; es decir, se dejaron de atender casi 1.800 participantes con sus familias por los motivos mencionados.

\section{Conclusiones}

Se evidencia que para desarrollar adecuadamente el tema de desplazamiento forzado falta contexto y una reflexión desde la perspectiva jurídica; desde 2007 y a la fecha aún se ignoran aspectos como la dinámica social y comercial de las localidades de Bogotá, en las cuales los negocios informales abundan y complementan la economía sectorial aportando solamente beneficios parciales (para las personas) y disminuyendo las expectativas macroeconómicas de crecimiento y desarrollo, y a su vez engrosan las cifras de desempleo y pobreza en general.

Adicionalmente, existe un problema de medición y cuantificación de las personas desplazadas que persiste actualmente, el cual debe ser objeto de reflexión a la hora de establecer criterios claros de reorientación de la política publica. Al respecto, Otálora (2008, p. 140) menciona:

Este aspecto -el de los métodos de registro de desplazados- es relevante de tener en cuenta en el momento de realizar un análisis sobre el fenómeno del desplazamiento forzado, y para trazar políticas públicas, por cuanto, dependiendo de la entidad generadora de la información, tanto la dimensión del fenómeno como las cifras pueden variar de manera significativa.

A pesar de que solamente se consideró el caso de una Oficina Operadora, se puede vislumbrar que para las demás oficinas operadoras la situación puede ser similar sin mencionar el contexto municipal en donde la falta de conocimiento por parte de los ejecutores locales y las condiciones culturales no permiten un adecuado seguimiento a la problemática ni a los precarios Programas de Generación de Ingresos.

Por su parte, en los indicadores estimados solamente se consideró el PGI -lo cual se puede considerar una evaluación parcial de la implementación de la política pública de atención al desplazamiento- y no el proceso previo ni el eje trasversal, lo cual evidencia la necesidad de la interdisciplinariedad para evaluar este tipo de programas y, de esta forma, garantizar un seguimiento y monitoreo adecuado.

Respecto de los porcentajes considerados de eficiencia, oportunidad y efectividad de la evaluación en términos parciales e integrales (50\% y $80 \%$, respectivamente), los resultados dan cuenta de que el PGI cumple parcialmente en $50 \%$ (es decir, es eficiente, oportuno y efectivo). Ahora, no se están considerando los procesos ni los procedimientos metodológicos, ni tampoco se están considerando otras variables de medición que 


\section{ČIF́F́ 26}

ISSN: 0124-3551 / Año 17, No 26 / enero-junio / pp. 175-218

afectan al programa pero que se consideran ajenos a él (por ejemplo, la contratación del personal idóneo, los procesos internos de las oficinas operadoras, las fallas del sistema, y todas aquellas variables de contexto que ni siquiera el PGI considera). Esto podría convertirse también en una evaluación parcial e integral más compleja pero que debe ser necesaria desarrollar para analizar en el menor tiempo posible y con más detalle cuál es la causa y qué variables intervienen en la inefectividad de los PGI.

Si bien la política publica de atención al desplazamiento ha sido reorientada por presión legal, mas no, inicialmente, por los análisis u evaluaciones realizadas, se puede decir que aún se esta en un proceso precario de construcción y participación colectiva inter e intra disciplinar respecto del tema; sin embargo, se percibe que la experiencia de las Oficinas Operadoras pudo haber sido utilizada como componente de análisis y de reorientación de los programas de la política pública.

Hasta aquí, se ha examinado este caso como un proceso analítico de carácter multicriterio que puede evidenciar las fallas de la implementación de un Programa de Generación de Ingresos -PGI- a partir de una serie de escenarios que deberían considerarse en el análisis, ejecución y evaluación de los componentes de la Política Pública de Atención al Desplazamiento. Esto ha dejado claro que, en términos de eficiencia económica pública, hace falta explorar, mejorar y proyectar los fundamentos positivos (Gobierno como organización) y analizar, consensuar y generar espacios efectivos de participación normativos (intervención del Estado en la actividad económica). 


\section{Referencias}

Acción Social, (n.d.). Programa de Generación de Ingresos [en línea]. [Fecha de consulta: 29 de octubre de 2009. Disponible en: http://www.accionsocial.gov.co/contenido/

Acción Social y CHF International Colombia (2008). Estudio sobre caracterización y sostenibilidad de los planes empresariales de generación de ingresos por el Convenio 082/07 - Resumen Ejecutivo.

Andrade, S. (2005). Diccionario de Economía. Tercera Edición. Lima: Editorial Andrade, p. 253.

Castro, M. (2006). El Análisis Multicriterio en la Evaluación de Políticas Públicas. En La Calidad del Gobierno - Evaluación económica de las políticas publicas (Eds.) (pp. 87 - 114). Madrid: España.

Colombia, Corte Constitucional (2004). "Sentencia T-025 de 2004".

Colombia. Congreso de la República (1997). "Ley 387 del 18 de julio de 1997”, por la cual se adoptan medidas para la prevención del desplazamiento forzado; la atención, protección, consolidación y estabilización socioeconómica de los desplazados internos por la violencia en la República de Colombia.

Comité Internacional de la Cruz Roja (CICR). Informe 2010 Colombia.

Consultoría para los Derechos Humanos y el Desplazamiento - CODHES. (2011). Boletín Informativo N No. 77. Bogotá 15 de febrero. www.codhes.org

Diccionario de Marketing. (1999). Edición 1999. España: Cultural S.A., Pág. 106.

Herazo, G. y Sellamén, A. (2010). El Capital Social y la problemática social en Colombia: Los Programas de Generación de Ingresos y El Desplazamiento Forzado. [Versión Electrónica]. Revista Criterio Libre Vol. 8, No. 13. Bogotá, Colombia. Julio - Diciembre 2010 , pp. $129-170$.

Ibáñez, A.M. y Moya, A. (2007). La población desplazada en Colombia: Examen de sus condiciones socioeconómicas y análisis de las políticas actuales (Misión para el diseño de una estrategia para la reducción de la pobreza y la desigualdad (MERPD), DNP). Bogotá.

Koontz, H. y Weihrich, H. (2004). Administración - Una Perspectiva Global. 12a. Edición. McGraw-Hill Interamericana. p. 14.

Mény Y. y Thoenig, J.C. (1992). Las Políticas Públicas. Barcelona: Ariel. 
Otálora, F.A. (2008). La Política Pública de Desplazamiento Forzado en Colombia Problemas de Medición y Magnitud del Desplazamiento. CRITERIOS - Cuadernos de Ciencias furídicas y Política Internacional (Vol.1. No. 2 pp.137-159). Bogotá: Universidad de San Buenaventura.

Parsons, W. (2007). Politicas Públicas. Una introducción a la teoría y la práctica del análisis de políticas publicas. Traducción al castellano: Atenea Acevedo Aguilar. FLACSO - México.

Programa de las Naciones Unidas para el Desarrollo - PNUD (2011). Desplazamiento Forzado Tierras y Territorios - Agendas Pendientes: La Estabilización Socioeconómica y la Reparación. Colección Cuadernos INDH 2011.

Ragin, C. C. (2007). La Construcción de la Investigación Social - Introducción a los métodos y su diversidad. Bogotá: Siglo del hombre Editores, Universidad de los Andes.

Theodore, L., Graham, A., Lindblom, G., Yehezkel, D., Amitai, E., Goodin, R., Waldner, I., Forester, J., Majone, G. y Meltsner, A. (1992). La Hechura de las Políticas. México: Ed. Luis F. Aguilar Villanueva, Grupo Editorial Miguel Angel Porrua..

Varela, B. E. (2005). La Mercantilización de lo Público - Ensayos sobre Gestión y Políticas Públicas. $1^{\text {a }}$ Edición. Programa Editorial Facultad de Ciencias de la Administración, Santiago de Cali: Universidad del Valle. 